\title{
Assessing the Thermal Tolerance and Growth Potential at Elevated Temperatures of Three Different Strains of Rainbow Trout (Oncorhynchus mykiss)
}

\author{
Michael A. Porto \\ West Virginia University
}

Follow this and additional works at: https://researchrepository.wvu.edu/etd

\section{Recommended Citation}

Porto, Michael A., "Assessing the Thermal Tolerance and Growth Potential at Elevated Temperatures of Three Different Strains of Rainbow Trout (Oncorhynchus mykiss)" (2012). Graduate Theses, Dissertations, and Problem Reports. 446.

https://researchrepository.wvu.edu/etd/446

This Thesis is protected by copyright and/or related rights. It has been brought to you by the The Research Repository @ WVU with permission from the rights-holder(s). You are free to use this Thesis in any way that is permitted by the copyright and related rights legislation that applies to your use. For other uses you must obtain permission from the rights-holder(s) directly, unless additional rights are indicated by a Creative Commons license in the record and/ or on the work itself. This Thesis has been accepted for inclusion in WVU Graduate Theses, Dissertations, and Problem Reports collection by an authorized administrator of The Research Repository @ WVU. For more information, please contact researchrepository@mail.wvu.edu. 


\title{
Assessing the Thermal Tolerance and Growth Potential at Elevated Temperatures of Three Different Strains of Rainbow Trout (Oncorhynchus mykiss)
}

\author{
Michael A. Porto \\ Thesis submitted to the \\ Davis College of Agriculture, Natural Resources and Design \\ at West Virginia University \\ in partial fulfillment of the requirements \\ for the degree of \\ Master of Science \\ in \\ Wildlife and Fisheries Resources \\ Kyle J. Hartman, Ph. D., Chair \\ Patricia M. Mazik, Ph. D. \\ Kenneth J. Semmens, Ph. D.
}

Division of Forestry and Natural Resources

Morgantown, WV

2012

Key Words: rainbow trout, Oncorhynchus mykiss, critical thermal maxima, growth rate, Case Western strain, Kamloop strain, Wytheville strain 


\title{
Abstract \\ Assessing the Thermal Tolerance and Growth Potential at Elevated Temperatures of Three Different Strains of Rainbow Trout (Oncorhynchus mykiss)
}

\author{
Michael A. Porto
}

This thesis examines how critical thermal maxima (CTM) differs between different strains of rainbow trout (Oncorhynchus mykiss) and explores the relationship between thermal tolerance and consumption, conversion efficiency, and growth rates at elevated temperatures. This thesis is comprised of three chapters; (1) an introduction and literature review on studies of temperature tolerance and growth in salmonids, (2) an experimental study investigating the CTM of three different strains of rainbow trout, and (3) an experimental study investigating the correlation between thermal tolerance and consumption, food conversion efficiency (FCE) and growth at elevated temperatures. For the first experimental study, we quantified the CTM of the Kamloop, Wytheville and Case Western strains of rainbow trout. The Case Western strain was of particular interest to us because it was thought to possess a higher thermal tolerance than other common strains of trout. We found that there were significant differences between the CTMs of the three strains and that the Case Western stain did have a higher thermal tolerance than the Kamloop and Wytheville strains (Mann-Whitney U; $p<0.003$ ). We also found a significant positive correlation between CTM and condition factor (linear regression; $\mathrm{p}<$ 0.001). In the second study, we determined consumption, FCE, and growth rates at temperatures of 20 and $22^{\circ} \mathrm{C}$ for individuals who's CTMs had previously been determined. We found that there were significant differences between the consumption, $\mathrm{FCE}$, and growth rates of the three strains at both temperatures (Two-way ANOVA; $p$ < 0.001). In general, the Case Western strain consumed, converted less efficiently, and grew less than the other two strains at both temperatures. We also found no significant correlations between individual CTM and consumption, FCE, or growth at either temperature. There was a slight trend in these correlations however. As individual CTM increased, consumption, FCE, and growth rates tended to decrease. This may indicate some tradeoff between the ability to survive and grow at these stressful temperatures. 


\section{Acknowledgements}

First of all, I would like to thank Dr. Kyle Hartman and West Virginia University's Division of Forestry and Natural Resources for accepting me into the program and allowing me to attend graduate school. And a special thanks to Dr. Hartman for all his help and guidance along the way as the chair of

my committee. I also must thank Dr. Pat Mazik and Dr. Ken Semmens for serving on my committee and for all their time and comments which helped me complete this thesis. I must also thank John Howell for all this help in the lab, and time spent assisting me with various tasks.

I would also like to thank all the other graduate students who made my time at WVU much more enjoyable (Andy, Ken, Ed, Jered, Niles, Jesse, Daniel, Brock, Alison, Eric, Geriann, John, Ross and everyone else) and for all their help throughout the course of this project. A big thanks also goes out to my family for their love and support through this process as well. And lastly, I would like to thank my wife-to-be Lauren for all her help in the lab and for her love and encouragement in my time at WVU. 


\section{Table of Contents}

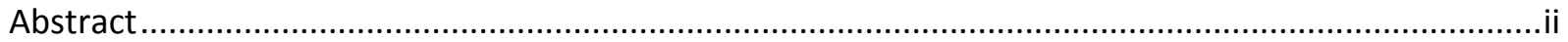

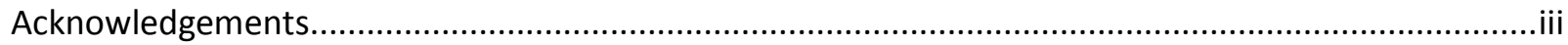

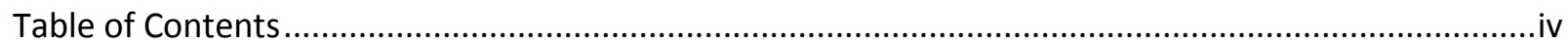

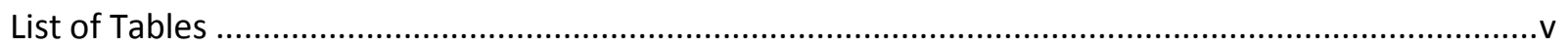

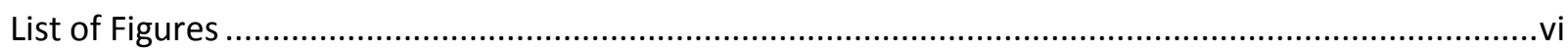

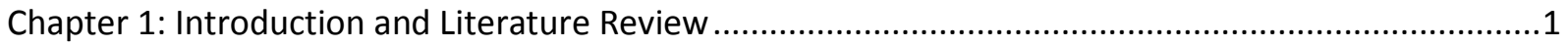

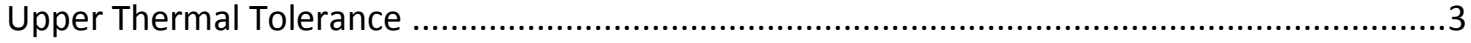

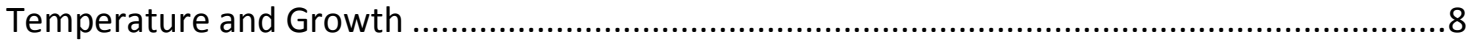

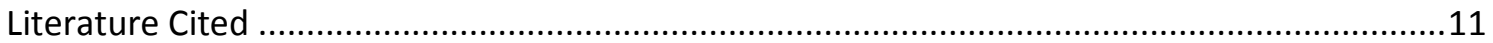

Chapter 2: Comparing the Critical Thermal Maxima of Three Different Strains of Rainbow Trout .........17

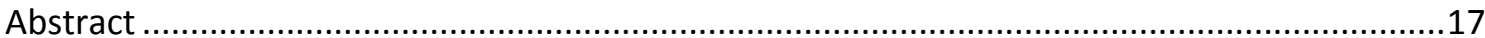

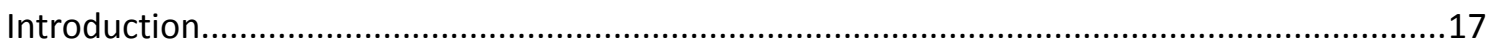

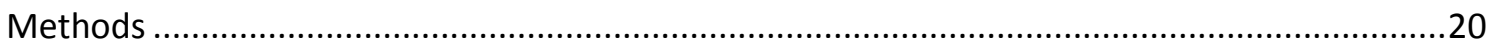

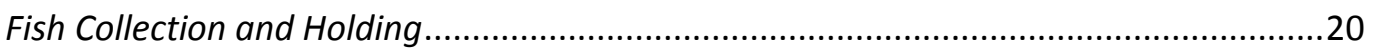

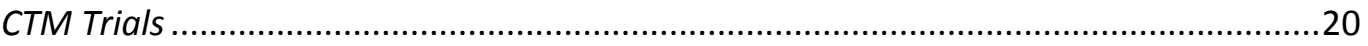

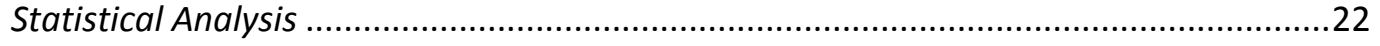

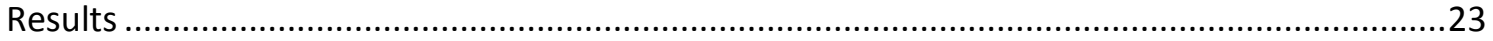

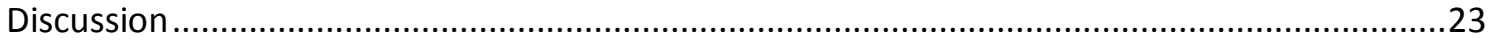

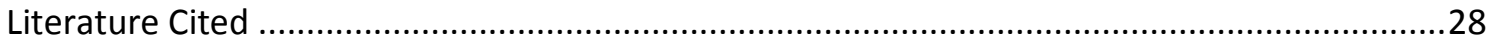

Chapter 3: Consumption, Food Conversion Efficiency and Growth at Elevated Temperatures.............36

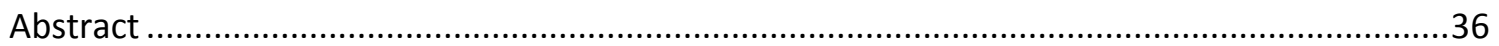

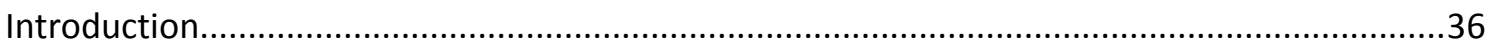

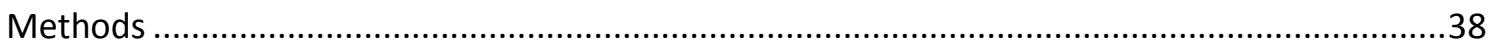

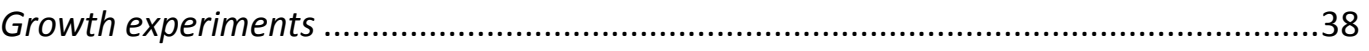

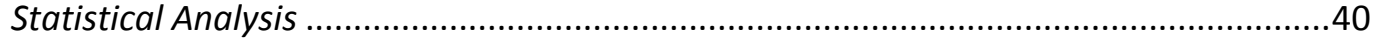

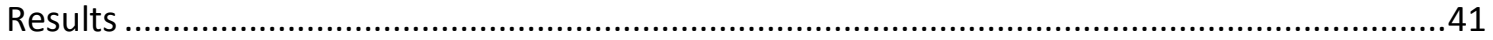

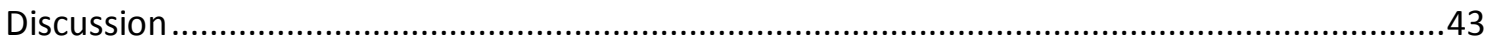

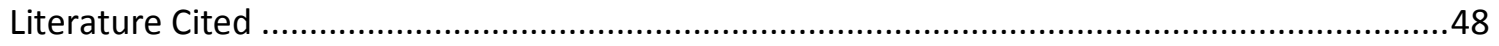

Appendix A: Summary of Results Using Size Corrected Data .....................................................59 


\section{List of Tables}

Table 1.1. Summary of past experimental studies investigating the upper thermal tolerance of rainbow trout.

Table 2.1. Mean ( \pm SEM) critical thermal maxima (CTM), total length, and wet weight of each strain.

Different superscripted letters indicate statistical differences $(p<0.05)$ in mean CTM.

Table 2.2. Summary of linear regression analysis relating CTM to length, wet weight and condition factor $(\mathrm{K})$. Superscripted ${ }^{*}$ indicates a significant relationship.

Table 2.3. Summary of ANCOVA results. Superscripted * indicates significance.

Table 3.1. Summary of water quality measurements taken over the course of growth experiments....51

Table 3.2. Mean ( \pm SEM) initial lengths and weights of fish used in growth experiments. .51

Table 3.3. Mean ( \pm SEM) consumption, food conversion efficiency (FCE) and growth rates of each strain at each test temperature. Statistical differences between strains within a temperature are denoted by different superscripted letters. Statistical differences between temperatures within a strain are denoted by *.

Table 3.4. Mean ( \pm SEM) consumption, food conversion efficiency (FCE) and growth rates of each strain at each test temperature in common aquaculture measures. .52

Table 3.5. Summary of linear regression analysis relating CTM to consumption, FCE and growth at 20 and $22^{\circ} \mathrm{C}$.

Table A.1 Mean ( \pm SEM) consumption, food conversion efficiency (FCE) and growth rates of each strain at each test temperature after being corrected for differences in initial size. Statistical differences between strains within a temperature are denoted by different superscripted letters. Statistical differences between temperatures within a strain are denoted by *

Table A.2. Summary of linear regression analysis relating CTM to consumption, FCE and growth at 20 and $22^{\circ} \mathrm{C}$. Data has been corrected for differences in initial size. 


\section{List of Figures}

Figure 2.1. Boxplots depicting the distribution (lowest observation, lower quartile, median, upper quartile, and largest observation) of individual CTM observations for each strain of rainbow trout. Circles represent statistical outliers.

Figure 2.2. Histogram showing the distribution of individual CTMs for each of the three strains. White bars represent individuals from the Kamloop strain, black bars represent individuals from the Wytheville strain, and gray bars represent individuals from the Case Western strain.

Figure 2.3. Scatterplot depicting the significant relationship of individual condition factors (K) vs. CTM ( $p$ $<0.001)$.

Figure 2.4. Scatterplot depicting the non-significant relationship between total length and CTM $(p=$ $0.08)$..

Figure 2.5. Scatterplot depicting the non-significant relationship between wet weight and CTM $(p=$ $0.53)$.

Figure 3.1. Scatter plot depicting the negative correlation between CTM and consumption among all individuals tested at $20^{\circ} \mathrm{C}$. This relationship was not significant $(p=0.82)$.

Figure 3.2. Scatter plot depicting the negative correlation between CTM and FCE among all individuals tested at $20^{\circ} \mathrm{C}$. This relationship was not significant $(p=0.21)$..

Figure 3.3. Scatter plot depicting the negative correlation between CTM and growth rate among all individuals tested at $20^{\circ} \mathrm{C}$. This relationship was not significant $(p=0.31)$.

Figure 3.4. Scatter plot depicting the negative correlation between CTM and consumption among all individuals tested at $22^{\circ} \mathrm{C}$. This relationship was not significant $(p=0.11)$.

Figure 3.5. Scatter plot depicting the negative correlation between CTM and FCE among all individuals tested at $22^{\circ} \mathrm{C}$. This relationship was not significant $(p=0.33)$.

Figure 3.6. Scatter plot depicting the negative correlation between CTM and growth rate among all individuals tested at $22^{\circ} \mathrm{C}$. This relationship was not significant $(p=0.10)$.

Figure A.1. Scatter plot depicting the negative correlation between CTM and consumption among all individuals tested at $20^{\circ} \mathrm{C}$ after being corrected for differences in initial size. This relationship was not significant $(p=0.30)$.

Figure A.2. Scatter plot depicting the negative correlation between CTM and FCE among all individuals tested at $20^{\circ} \mathrm{C}$ after being corrected for differences in initial size. This relationship was not significant ( $p$ $=0.21$. 
Figure A.3. Scatter plot depicting the negative correlation between CTM and growth rate among all individuals tested at $20^{\circ} \mathrm{C}$ after being corrected for differences in initial size. This relationship was not significant $(p=0.15)$.

Figure A.4. Scatter plot depicting the negative correlation between CTM and consumption among all individuals tested at $22^{\circ} \mathrm{C}$ after being corrected for differences in initial size. This relationship was not significant $(p=0.06)$.

Figure A.5. Scatter plot depicting the negative correlation between CTM and FCE among all individuals tested at $22^{\circ} \mathrm{C}$ after being corrected for differences in initial size. This relationship was not significant ( $p$ $=0.33)$.

Figure A.6. Scatter plot depicting the negative correlation between CTM and growth rate among all individuals tested at $22^{\circ} \mathrm{C}$ after being corrected for differences in initial size. This relationship was not significant $(p=0.08)$. 


\section{Chapter 1: Introduction and Literature Review}

This thesis examines how critical thermal maxima (CTM) differs between different strains of rainbow trout (Oncorhynchus mykiss) and explores the relationship between thermal tolerance and consumption, conversion efficiency, and growth rates at elevated temperatures. This thesis is comprised of three chapters; (1) an introduction and literature review on studies of temperature tolerance and growth in salmonids, (2) an experimental study investigating the CTM of three different strains of rainbow trout, and (3) an experimental study investigating the correlation between thermal tolerance and consumption, food conversion efficiency (FCE) and growth at elevated temperatures. This relationship between thermal tolerance and consumption, conversion efficiency and growth at elevated temperatures has not been investigated to our knowledge and could provide valuable information for fisheries managers and aquaculturists alike. Our hypothesis is that individuals with higher thermal tolerances will grow better at elevated temperatures when compared to individuals with lower thermal tolerances.

A fish's thermal environment is thought to have a greater impact on its distribution, overall condition, and survival than any other aquatic habitat characteristic (Wootton 1998). In addition to lethal effects, temperature has sub-lethal effects that can adversely affect metabolism (Brett 1971), feeding and activity rates (Ojanguren et al. 2001), and in turn growth (Elliot 1975; Lobon-Cervia and Rincon 1998). This is especially true for rainbow trout and other salmonids that are cold water species and only tolerate a relatively small range of temperatures. Being poikilotherms, trout cannot regulate their own body temperature and are completely dependent on suitable habitat being available to survive and grow. Unfortunately, the amount of suitable habitat available for cold water species is decreasing for a variety of reasons. Increasing air temperatures due to greenhouse gasses (Eaton and Scheller 1996; Morrill et al. 2005), urbanization (Nelson and Palmer 2007), deforestation (Baillie et al. 
2005; Brown and Krygier 1970; Studinski 2010), and other anthropogenic activities are major threats to raise ambient water temperatures across the United States.

Identification of individuals or an entire strain of trout that tolerates and grows well under stressful temperatures would be valuable for restoring trout to streams that no longer support trout populations. Eaton and Scheller (1996) predict that with a doubling of atmospheric carbon dioxide (CO2), rainbow trout could lose up to $49.1 \%$ of their current habitat due to a rise in stream temperatures across the country. A similar study looking only at trout distribution in the southern Appalachians found that even with a small increase of $0.5^{\circ} \mathrm{C}$ in air temperature, trout will begin to lose suitable habitat (Flebbe et al. 2006). The information from our study will also be valuable to the aquaculture industry where rainbow trout are now produced all over the world (every continent except Antarctica) and production topped 700,000 tons in 2009 according to the United Nations Food and Agriculture Organization (FAO 2006-2012). Individuals or strains that tolerate or grow better at elevated temperatures would allow aquaculturists to increase profits through longer growing seasons and shorter duration to harvest.

One strain that reportedly tolerates and performs well at stressful temperatures is the Case Western strain of rainbow trout. This strain is the only registered strain of rainbow trout that originates from a warm water broodstock according to the National Fish Strain Registry (Kincaid et al. 2001). The discovery of the strain was the byproduct of ecological pond experiments conducted by Dr. Mitsuo Teraguchi at Case Western Reserve University in the early 1980's. The trout were placed in experimental ponds as predators in an experiment over the course of the summer. When the fish were recovered in the fall, the researchers realized that the trout had survived temperatures that were thought to be lethal to rainbow trout. These fish were then kept as a brood stock and the strain was later registered as a warm tolerant strain of rainbow trout (Ken Semmens, West Virginia University, 
personal communication). According to Dan Miller who worked with these fish for several years at West Virginia University (WVU), the Case Western strain tolerates high temperatures better than other strains of rainbow trout and grow well at temperatures near the reported upper thermal tolerance of rainbow trout $\left(25-26^{\circ} \mathrm{C}\right)$ in an aquaculture setting (personal communication). Since the strain was sold in the early 1990's to Laurel Hill Trout Farm, Inc., there has been no selection for thermal tolerance placed on the individuals of this strain. This lead to the question of whether or not these fish still possess this thermal tolerance or if it has been lost due to a lack of selective pressure. Comparing thermal tolerance of the Case Western strain to the thermal tolerance of other strains of rainbow trout and investigating the relationship between tolerating and growing at stressful temperatures are the main foci of this thesis.

\section{Upper Thermal Tolerance}

Historically, rainbow trout are found to prefer water temperatures between $11.3^{\circ} \mathrm{C}$ (McCauley et al. 1977) and $19^{\circ} \mathrm{C}$ (Myrick and Cech 2000). This wide range in preferred temperature is most often attributed to the recent thermal history of the individual or population (Javaid and Anderson 1967), but may also be due in some part to genetic variation. The same kind of variation can be observed when looking at the upper thermal tolerance of this species. Studies have found the upper thermal tolerance of rainbow trout to be between 24 (Eaton et al. 1995) and $32^{\circ} \mathrm{C}$ (Myrick and Cech 2000). While this variability may be due in part to genetic differences, most of this variation is attributed to the recent thermal history of the fish or the method being used to determine thermal tolerance (Beitinger and Bennett 2000).

The two most common methods to determine upper thermal tolerance are critical thermal maximum (CTM) and upper incipient lethal temperature (UILT). While there are other ways to estimate thermal tolerance (i.e., field observations, model simulations), the UILT and CTM method are most often 
used. Both tests are similar in that they use random samples of fish and expose them to near lethal temperatures, but they are very different in their methodologies and results. The UILT method was developed by Fry et al. (1942) and was based on the $\mathrm{LD}_{50}$ from the field of toxicology. This method consists of sudden immersions of groups of fish from various acclimation temperatures into test temperatures and recording mortality over time. The thermal tolerance of the species is then determined by fitting regression lines to the data and estimating the temperature that would be lethal to $50 \%$ of the population over a certain period of time (Beitinger and Bennett 2000).

The CTM method was initially developed by Cowles and Bogert (1944) on reptiles, but has since been critiqued (Lutterschmidt and Hutchinson 1997) and modified to be used on freshwater fish (Becker and Genoway 1979). The CTM method consists of the acclimation of fish to a certain temperature after which the water is heated at a constant rate from the acclimation temperature to a select endpoint. This can either be the point where the fish loses the ability to remain upright in the water column, the onset of spasms, or the cessation of opercular movement (Becker and Genoway 1979). This is an advantage of the CTM because by selecting loss of equilibrium as the endpoint for the experiment, fish can be returned to cooler water after the trial where they can recover. This can be especially applicable when working with individuals from an endangered or threatened species (Brandt et al. 1993). Other methods generally use death as the endpoint for experiments.

In order to make direct comparisons of upper thermal tolerance between studies, one must not only take into account the method used (CTM, UILT, field observation etc.), but they must also consider acclimation temperature, photoperiod, selected endpoint and rate of temperature change if using the CTM method (Beitinger et al. 2000). Differences in acclimation temperatures can cause significant differences in upper thermal tolerances (Carveth et al. 2006). As the acclimation temperature increases, fish typically gain upper thermal tolerance and lose lower thermal tolerance. In a similar manner, fish 
tend to lose upper thermal tolerance and gain lower thermal tolerance as acclimation temperature decreases (Beitinger and Bennett 2000). Fish also tend to exhibit higher thermal tolerances under the presence of longer photoperiods which mimic warmer months of the year (Hutchison 1961). The selected endpoint can also have a pronounced effect on the perceived upper thermal tolerance of a species (Beitinger et al. 2000). Loss of equilibrium is usually the first to occur, followed by the onset of spasms and ultimately death. Those studies using loss of equilibrium will generally report lower upper thermal tolerance values than those who use onset of spasms or death as the select endpoint (Becker and Genoway 1979). And lastly, the rate at which the water is heated can cause differences in upper thermal tolerance values. Becker and Genoway (1979) suggest that a heating rate of $0.3^{\circ} \mathrm{C} / \mathrm{min}$ gives the most accurate and repeatable results and this rate is reported most often in the literature. If the heating rate is faster or slower than $0.3^{\circ} \mathrm{C} / \mathrm{min}$ the results of the test will indicate an upper thermal tolerance higher than the actual value (Beitinger et al. 2000).

Many studies have been done on the thermal tolerance of rainbow trout with a relatively wide range of results (Table 1.1) due in some part to differences in the above criteria. Using a field information-based system Eaton et al. (1995) estimated the upper thermal tolerance of rainbow trout to be $24^{\circ} \mathrm{C}$ while Raleigh et al. (1984) suggests their upper thermal tolerance to be $25^{\circ} \mathrm{C}$. An experimental study by Hokanson et al. (1977) using the UILT method found the upper thermal tolerance of a Lake Superior strain of rainbow trout to be $25.6^{\circ} \mathrm{C}$ when acclimated to $16^{\circ} \mathrm{C}$. In another study employing the UILT method, Cherry et al. (1977) found that rainbows have an upper thermal tolerance of $25^{\circ} \mathrm{C}$ when acclimated to $24^{\circ} \mathrm{C}$. Kaya (1978) used the UILT method and found that rainbow trout living in the geothermally heated Firehole River in Yellowstone National Park had a similar upper thermal tolerance to two hatchery strains of rainbow trout. Upper temperature tolerances for all acclimation temperatures were between 23.2 and $26.2^{\circ} \mathrm{C}$. Kaya found significantly different elevations in the regression lines between the Firehole trout and the two hatchery strains at acclimation temperatures of 
$5,9,13$, and $17^{\circ} \mathrm{C}$, but not at acclimation temperatures of 21 and $24.5^{\circ} \mathrm{C}$. She deemed these differences as not ecologically significant because of the small temperature difference and the fact that the Firehole trout rarely if ever experienced temperatures as low as 5 and $9^{\circ} \mathrm{C}$ and only experience 13 , and $17^{\circ} \mathrm{C}$ in the winter when temperatures would never rise to near lethal temperatures.

In a study looking at the effects of sublethal exposure to nickel, Becker and Wolford (1980) found using the CTM method that the upper thermal tolerance of their control rainbow trout to be $26.9^{\circ} \mathrm{C}$ when acclimated to $8^{\circ} \mathrm{C}$ and heated at a rate of $0.1^{\circ} \mathrm{C} / \mathrm{min}$. In a study looking at the thermal tolerances of five species of trout inhabiting the southwestern United States, Lee and Rinne (1980) found the CTM of rainbow trout acclimated to 10 and $20^{\circ} \mathrm{C}$ to be 28.45 and $29.35^{\circ} \mathrm{C}$ respectively. While investigating the effects of fluctuating acclimation temperature as opposed to a constant acclimation temperature, Threader and Houston (1983) found the UILT of their rainbow trout to be $25.9^{\circ} \mathrm{C}$ when acclimated to $20^{\circ} \mathrm{C}$. Using a variation of the CTM method in which temperatures were increased at a rate of $.5^{\circ} \mathrm{C} /$ day, Sonski (1984) found the lethal temperature for two different strains of rainbow trout acclimated to several temperatures. When acclimated to 15,20 and $23^{\circ} \mathrm{C}$, the lethal temperature for Wytheville strain rainbow trout was $27,26.8$ and $27^{\circ} \mathrm{C}$ respectively. For Firehole River rainbows he found that their lethal temperature was $27.4,27.2$ and $26.3^{\circ} \mathrm{C}$ when acclimated to 15,20 and $23^{\circ} \mathrm{C}$ respectively. This study was in agreement with Kaya (1978) in that both studies indicated that in laboratory trials, the Firehole River strain showed no significant advantage over a stock strain of rainbows. In a study investigating the effects of stress on thermal tolerance, Strange et al. (1993) found the CTM of rainbows acclimated to $15^{\circ} \mathrm{C}$ to be $29.4^{\circ} \mathrm{C}$. This was the control group of fish and fish subjected to confinement or electroshock prior to the thermal challenge showed no significant difference in thermal tolerance. 
More recently, a study conducted by Currie et al. (1998) found the CTM of rainbow trout acclimated to 10,15 and $20^{\circ} \mathrm{C}$ to be $28,29.1$ and $29.8^{\circ} \mathrm{C}$, respectively. This study has important implications on our study because the same acclimation temperature and heating rate were used. We would expect to find results similar to the $20^{\circ} \mathrm{C}$ acclimation group $\left(29.8^{\circ} \mathrm{C}\right)$. Myrick and Cech (2000) conducted an extensive study into the physiology and performance of rainbow trout at a variety of temperatures. They examined the Eagle Lake strain and Mt. Shasta strain and found that at acclimation temperatures of $10,14,19,19,22$, and $25^{\circ} \mathrm{C}$ the Eagle Lake strain had mean CTM's of 27.6, 28.6, 29.6, $30.6,31$, and $32^{\circ} \mathrm{C}$ respectively. When acclimated to the same temperatures, the Mt. Shasta strain had mean CTM's of $27.7,28.4,29.3,30,30.7$, and $31.5^{\circ} \mathrm{C}$. Again, they determined that there were no significant differences in the CTM's of the two strains. Another study conducted by Carline and Machung (2001) explored potential differences in thermal tolerance between wild and domestic strains of trout found that the CTM for wild rainbow trout acclimated to $9.8^{\circ} \mathrm{C}$ was $28.1^{\circ} \mathrm{C}$. The $\mathrm{CTM}$ for a domestic strain acclimated to the same temperature was found to be $27.6^{\circ} \mathrm{C}$. This difference was statistically significant prompting them to suggest that the difference was due to genetic factors. In another study conducted by Myrick and Cech (2005) the CTM for Nimbus strain steelhead was determined at three different acclimation temperatures. At temperatures of 11,15 and $19^{\circ} \mathrm{C}$, their CTM was found to be $27.5,28.4$ and $29.6^{\circ} \mathrm{C}$, respectively. In a study looking at the effects of various organic chemicals on the thermal tolerance of several fish species, Patra et al. (2007) found the CTM of rainbow trout to be $30.7^{\circ} \mathrm{C}$ when acclimated to $10^{\circ} \mathrm{C}$.

From the above literature, it is evident that different methods and different strains of fish produce different results. The question remains however, how much of that variation is due to genetic factors and how much is owed to differing methods? Wahl (1974) found significant differences in mean times to death among 6 strains of brook trout (Salvelinus fontinalis) exposed to $27.5^{\circ} \mathrm{C}$ water. These findings are significant because he determined through repetition of experiments and experiments 
between inbred and outbred strains that upper thermal tolerance is very likely determined genetically and that it does differ between different strains of the same species. Research done by Carline and Machung (2001) echoed these findings that thermal tolerance is genetically linked. More recently, Ineno et al. (2005) showed that through generations of selective breeding a rainbow trout strain developed a marginally higher thermal tolerance than two unselected strains. This work strongly suggests a genetic basis to thermal tolerance and that it can differ between different strains of the same species.

\section{Temperature and Growth}

Temperature has very well documented effects on the growth of rainbow trout (Bear 2005; Grabowski 1973; Hokanson et al. 1977; Myrick and Cech 1999; Myrick and Cech 2000; Myrick and Cech 2005; Railsback and Rose 1999; Sadler et al. 1986; Wurtsbaugh and Davis 1977). Beginning with very low temperatures, growth increases with increasing temperatures up to an optimum temperature where growth rates are maximized. The optimum temperature for growth and consumption is often the temperature of greatest variance in these parameters as well. Variance in growth rates decrease as temperatures rise or fall from this optimum temperature (Hartman and Hayward 2007). Beyond this optimum temperature however, growth rates decline relatively rapidly to zero as temperature continues to increase (Bear 2005; Hokanson et al. 1977; Railsback and Rose 1999). Due to this fact, it is logical that rainbow trout will select temperatures around this optimum if they are available. Many times however, these optimal temperatures are not available and trout are forced to live in suboptimal temperatures which ultimately lead to decreased growth rates.

Many studies have documented differences in growth rates between different strains of rainbow trout (Ayles and Baker 1983; Klupp 1979; McKay et al. 1984; Myrick and Cech 2000; Sadler et al. 1986). Sadler et al. (1986) found differences in growth rates between two strains of rainbow trout and 
determined these differences were due to genetic disparities. They found that the strains that had undergone more domestication or had spent more time in a hatchery setting had higher growth rates suggesting that this was a favorable genetic characteristic that could be selected for. McKay et al. (1984) ranked 35 different strains of rainbow trout based on their growth rates at 7 and $15^{\circ} \mathrm{C}$. They found that strains did not necessarily attain the same rank during the $7^{\circ} \mathrm{C}$ trial as they did during the $15^{\circ} \mathrm{C}$ trial. This could be due to the fact that fish that grew well in the first trial reached a larger size, decreasing their growth rates in the subsequent test. However, it may be evidence that strains perform differently at different temperatures. Likewise, Ayles and Baker (1983) found significant differences between the growth rates of strains of rainbow trouts stocked into small lakes on the Canadian prairie.

Much less attention has been paid to the differences between strains under the effect of stressful temperatures. In a study looking at various physiological processes and how they are affected by temperature, Myrick and Cech (2000) found that Mt. Shasta strain rainbow trout grew significantly better than Eagle Lake rainbow trout at 22 and $25^{\circ} \mathrm{C}$ and had higher consumption rates under these stressful temperatures as well. They suggest that these differences may be due to differences in rearing site elevation or genetic discrepancies. Ojanguren et al. (2001) found that certain families of brown trout (Salmo trutta) had different growth and consumption rates across a range of temperatures. Families that performed well did so across all temperatures implying that there was not a tradeoff between elevated growth at optimal temperatures and growth at non-optimal temperatures. In another study examining the effects of temperature on brown trout growth, Lobon-Cervia and Rincon (1998) found that brown trout populations in Spain had slower decreases in growth rates above the optimal growth temperature when compared to extensive work done by Elliot et al. (1995). Again, this suggests possible thermal adaptation by a population of trout. 
In summary, there is evidence that thermal tolerance can vary within and between strains of the same species (Carline and Machung 2001; Wahl 1974). Work done by Myrick and Cech (2000) also indicates that growth can differ between different strains of the same species at stressful temperatures. If this is the case, we expect to see that those individuals who tolerate higher temperatures will also grow faster and more efficiently at these temperatures. We expect this because if they have a higher CTM, they likely have a wider range of preferred temperatures and are more comfortable at higher temperatures (Jobling 1981). Therefore, metabolic costs should be lower for these individuals at elevated temperatures when compared to fish with lower CTMs. The following two chapters are comprised of an experimental chapter comparing the CTMs of three different strains of rainbow trout as well as an experimental chapter investigating strain related differences in consumption, conversion efficiency and growth at elevated temperatures and the relationship between CTM and these parameters. 


\section{Literature Cited}

Ayles, G. B. and R. F. Baker. 1983. Genetic differences in growth and survival between strains and hybrids of rainbow trout (Salmo gairdneri) stocked in aquaculture lakes in the Canadian prairies. Aquaculture 33: 269-280.

Baillie, B. R., K. J. Collier and J. Nagels. 2005. Effects of forest harvesting and woody debris removal on two Northland streams, New Zealand. New Zealand Journal of Marine and Freshwater Research 39(1): 1-15.

Bear, B. A. 2005. Effects of temperature on survival and growth of westslope cutthroat trout and rainbow trout: implications for conservation and restoration. Master's thesis. Montana State University. $68 \mathrm{pp}$.

Becker, C. D. and R. G. Genoway. 1979. Evaluation of the critical thermal maximum for determining thermal tolerance of freshwater fish. Environmental Biology of Fishes 4(3): 245-256.

Becker, C.D. and M.G. Wolford. 1980. Thermal resistance of juvenile salmonids sublethally exposed to nickel, determined by the critical thermal maximum method. Environmental Pollution 21: 181189.

Beitinger, T. L. and W. A. Bennett. 2000. Quantification of the role of acclimation temperature in temperature tolerance of fishes. Environmental Biology of Fishes 58(3): 277-288.

Beitinger, T. L., W. A. Bennett and R.W. McCauley. 2000. Temperature tolerances of North American freshwater fishes exposed to dynamic changes in temperature. Environmental Biology of Fishes 58(3): 237-275.

Brandt, T. M., K. G. Graves, C. S. Berkhouse, T. P. Simon and B. G. Whiteside. 1993. Laboratory spawning and rearing of the endangered fountain darter. Progressive Fish-Culturist 55(3): 149156.

Brett, J. R. 1971. Energetic responses of salmon to temperature. A study of some thermal relations in the physiology and freshwater ecology of sockeye salmon (Oncorhynchus nerka). American Zoologist 11(1): 99-113.

Brown, G. W., and J. T. Krygier. 1970. Effects of Clear-Cutting on Stream Temperature. Water Resources Research 6(4), 1133-1139.

Carline, R.F. and J. F. Machung. 2001. Critical Thermal Maxima of Wild and Domestic Strains of Trout. Transactions of the American Fisheries Society 130: 1211-1216.

Carveth, C. J., A. M. Widmer and S. A. Bonar. 2006. Comparison of upper thermal tolerances of native and nonnative fish species in Arizona. Transactions of the American Fisheries Society 135: 14331440.

Cherry, D. S., K. L. J. Dickson and J. Cairns Jr. 1977. Preferred, avoided, and lethal temperatures of fish during rising temperature conditions. Journal of the Fisheries Research Board of Canada 34: 239-246.

Cowles, R. B. and C. M. Bogert. 1944. A preliminary study of the thermal requirements of desert reptiles. Bulletin of the American Museum of Natural History 83:261-296. 
Currie, R. J., W. A. Bennett and T.L. Beitinger. 1998. Critical thermal minima and maxima of three freshwater game-fish species acclimated to constant temperatures. Environmental Biology of Fishes 51(2): 187-200.

Eaton, J. G. and R. M. Scheller. 1996. Effects of climate warming on fish thermal habitat in streams of the United States. Limnology and Oceanography 41(5): 1109-1115.

Eaton, J. G., J. H. McCormick, B. E. Goodno, D. G. O'Brien, H. G. Stefany, M. Hondzo, and R. M. Scheller. 1995. A field information-based system for estimating fish temperature tolerances. Fisheries 20(4)10-18.

Elliot, J. M. 1975. The growth rate of brown trout (Salmo trutta L.) fed on maximum rations. Journal of Animal Ecology 44(3): 805-821.

Elliott, J. M., M. A. Hurley, and R. J. Fryer. 1995. A new, improved growth model for brown trout Salmo trutta. Functional Ecology 9:290-298.

FAO. (C) 2006-2012. Fisheries and Aquaculture Department. In: FAO Fisheries and Aquaculture Department [online]. Rome. Updated 8 November 2011. http://www.fao.org/fishery/culturedspecies/Oncorhynchus_mykiss/en

Flebbe, P. A., L. D. Roghair and J. L. Bruggink. 2006. Spatial modeling to project southern Appalachian trout distribution in a warmer climate. Transactions of the American Fisheries Society 135: 1371-1382.

Fry, F.E.J., J.R. Brett and G.H. Clawson. 1942. Lethal limits of temperature for young goldfish. Rev. Can. Biol. 1: 50-56.

Grabowski, S. J. 1973. Effects of fluctuating and constant temperatures on some hematological characteristics, tissue glycogen levels, and growth of steelhead trout (Salmo gairdneri). Ph. D. dissertation. University of Idaho. $77 \mathrm{pp}$.

Hartman, K. J. and R. S. Hayward. 2007. Bioenergetics. Pages 515-560 in C. S. Guy and M. L. Brown, editors. Analysis and interpretation of freshwater fisheries data. American Fisheries Society, Bethesda, Maryland.

Hokanson, K. E. F., C. F. Kleiner and T.W. Thorslund. 1977. Effects of constant temperatures and diel temperature fluctuations on specific growth and mortality rates and yield of juvenile rainbow trout, Salmo gairdneri. Journal of the Fisheries Research Board of Canada 34: 639-648.

Hutchison, V. H. 1961. Critical Thermal Maxima in Salamanders. Physiological Zoology34: 92-125.

Ineno, T., S. Tsuchida, M. Kanda and S. Watabe. 2005. High temperature tolerance of rainbow trout Oncorhynchus mykiss selected by high temperature breeding. Fisheries Science 71: 767-775.

Javaid, M. Y., and J. M. Anderson. 1967. Thermal acclimation and temperature selection in Atlantic salmon, Salmo salar, and rainbow trout, S. gairdneri. Journal of the Fisheries Research Board of Canada 24:1507-1513.

Jobling, M. 1981. Temperature tolerance and the final preferendum - rapid methods for assessment of optimum growth temperatures. Journal of Fish Biology 19: 439-455.

Kaya, C. M. 1978. Thermal resistance of rainbow trout from a permanently heated stream, and of two hatchery strains. The Progressive Fish-Culturist 40(4): 138-142.

Kincaid, H. L., L. J. Mengel and S. Brimm. 2001. National Fish Strain Registry - Trout, species tables of reported strains and broodstocks. USFWS. 
Klupp, R. 1979. Genetic variance for growth in rainbow trout (Salmo gairdneri). Aquaculture 18(2): 123134.

Lee, R. M. and J. N. Rinne. 1980. Critical thermal maxima of five trout species in the southwestern United States. Transactions of the American Fisheries Society 109(6): 632-635.

Lobon-Cervia, J. and P. A. Rincon. 1998. Field assessment of the influence of temperature on growth rate in a brown trout population. Transactions of the American Fisheries Society 127:718-728.

Lutterschmidt, W. I. and V. H. Hutchison. 1997. The critical thermal maximum: history and critique. Canadian Journal of Zoology 75(10): 1561-1574.

McCauley, R. W., J. R. Elliott and L.A.A. Read. 1977. Influence of acclimation temperature on preferred temperature in the rainbow trout Salmo gairdneri. Transactions of the American Fisheries Society 106(4): 362-365.

McKay, L. R., G. W. Friars and P. E. Ihssen. 1984. Genotype x Temperature interactions for growth of rainbow trout. Aquaculture 41: 131-140.

Morrill, J. C., R. C. Bales and M. H. Conklin. 2005. Estimating stream temperature from air temperature: implications for future water quality. Journal of Environmental Engineering 131(1): 131-139.

Myrick, C. A. and J. J. Cech. 1999. Effects of ration size and temperature on the bioenergetics of juvenile California steelhead, Oncorhynchus mykiss.

Myrick, C. A. and J. J. Cech Jr. 2000. Temperature influences on California rainbow trout physiological performance. Fish Physiology and Biochemistry 22(3): 245-254.

Myrick, C. A. and J. J. Cech. 2005. Effects of temperature on the growth, food consumption, and thermal tolerance of age-0 Nimbus-strain steelhead. North American Journal of Aquaculture 67:324-330.

Nelson, K. C. and M. A. Palmer. 2007. Stream temperature surges under urbanization and climate change: data, models, and responses. Journal of the American Water Resources Association 43(2): 440-452.

Ojanguren, A. F., F. G. Reyes-Gavilán and F. Brana. 2001. Thermal sensitivity of growth, food intake and activity of juvenile brown trout. Journal of Thermal Biology 26(3): 165-170.

Patra, R. W., J. C. Chapman, R. P. Lim, and P. C. Gehrke. 2007. The effects of three organic chemicals on the upper thermal tolerances of four freshwater fishes. Environmental Toxicology and Chemistry 26: 1454-1459.

Railsback, S. F. and K. A. Rose. 1999. Bioenergetics modeling of stream trout growth: temperature and food consumption effects. Transactions of the American Fisheries Society 128(2): 241-256.

Raleigh, R. F., T. Hickman, R. C. Solomon, and P. C. Nelson. 1984. Habitat suitability information: rainbow trout. , United States Fish and Wildlife Service. 64 pp.

Sadler, S. E., G. W. Friars, and P. E. Ihssen. 1986. The influence of temperature and genotype on the growth rate of hatchery-reared salmonids. Canadian Journal of Animal Sciences 66: 599-606.

Sonski, A. J. 1984. Comparison of heat tolerances of redband trout, Firehole River rainbow trout, and Wytheville rainbow trout. Annual Proceedings of the Texas Chapter of the American Fisheries Society 6: 27-35.

Strange, R. J., R. B. Petrie and J. J. Cech Jr. 1993. Slight stress does not lower critical thermal maximums in hatchery-reared rainbow trout. Folia Zoologica 42(3): 251-256. 
Studinski, J. M. 2010. The effects of riparian tree harvest intensity and woody debris addition on biotic and abiotic stream characteristics. Ph. D. Dissertation. West Virginia University. 98 pp.

Threader, R. W. and A. H. Houston. 1983. Heat tolerance and resistance in juvenile rainbow trout acclimated to diurnally cycling temperatures. Comparative Biochemistry and Physiology Part A: Physiology 75(2): 153-155.

Wahl, R. W. 1974. Heat tolerance in strains of brook trout (Salvelinus fontinalis). Ph. D. Dissertation. The Pennsylvania State University. $90 \mathrm{pp}$.

Wootton, R.J. 1998. The ecology of teleost fishes. 2nd edition. Fish \& Fisheries Series, no. 24. Dordrecht: Kluwer.

Wurtsbaugh, W. A. and G. E. Davis. 1977. Effects of temperature and ration level on the growth and food conversion efficiency of Salmo gairdneri, Richardson. Journal of Fish Biology 11(2): 87-98. 
Table 1.1. Summary of past experimental studies investigating the upper thermal tolerance of rainbow trout.

\begin{tabular}{|c|c|c|c|c|}
\hline Author(s) & Origin of Fish & Method & $\begin{array}{c}\text { Acclimation } \\
\text { Temperature } \\
\left({ }^{\circ} \mathrm{C}\right)\end{array}$ & $\begin{array}{c}\text { Upper } \\
\text { Thermal } \\
\text { Tolerance } \\
\left({ }^{\circ} \mathrm{C}\right) \\
\end{array}$ \\
\hline $\begin{array}{l}\text { Hokanson et al. } \\
\text { (1977) }\end{array}$ & Lake Superior & UILT & 16 & 25.6 \\
\hline Cherry et al. (1977) & & UILT & 24 & 25 \\
\hline \multirow[t]{18}{*}{ Kaya (1978) } & Firehole River, MT & UILT & 5 & 25 \\
\hline & Firehole River, MT & UILT & 9 & 25.2 \\
\hline & Firehole River, MT & UILT & 13 & 25.2 \\
\hline & Firehole River, MT & UILT & 17 & 25.7 \\
\hline & Firehole River, MT & UILT & 21 & 26.2 \\
\hline & Firehole River, MT & UILT & 24.5 & 26.2 \\
\hline & Ennis National Fish Hatchery, MT & UILT & 5 & 23.7 \\
\hline & Ennis National Fish Hatchery, MT & UILT & 9 & 24.2 \\
\hline & Ennis National Fish Hatchery, MT & UILT & 13 & 25.2 \\
\hline & Ennis National Fish Hatchery, MT & UILT & 17 & 25.7 \\
\hline & Ennis National Fish Hatchery, MT & UILT & 21 & 26.2 \\
\hline & Ennis National Fish Hatchery, MT & UILT & 24.5 & 26.2 \\
\hline & $\begin{array}{l}\text { Bozeman Fish Cultural Development } \\
\text { Center, MT }\end{array}$ & UILT & 5 & 23.2 \\
\hline & $\begin{array}{c}\text { Bozeman Fish Cultural Development } \\
\text { Center, MT }\end{array}$ & UILT & 9 & 24.7 \\
\hline & $\begin{array}{c}\text { Bozeman Fish Cultural Development } \\
\text { Center, MT }\end{array}$ & UILT & 13 & 24.7 \\
\hline & $\begin{array}{c}\text { Bozeman Fish Cultural Development } \\
\text { Center, MT }\end{array}$ & UILT & 17 & 25.2 \\
\hline & $\begin{array}{c}\text { Bozeman Fish Cultural Development } \\
\text { Center, MT }\end{array}$ & UILT & 21 & 25.7 \\
\hline & $\begin{array}{c}\text { Bozeman Fish Cultural Development } \\
\text { Center, MT }\end{array}$ & UILT & 24.5 & 26.2 \\
\hline $\begin{array}{l}\text { Becker and Wolford } \\
(1980)\end{array}$ & & CTM & 8 & 26.9 \\
\hline \multirow[t]{2}{*}{$\begin{array}{c}\text { Lee and Rinne } \\
(1980)\end{array}$} & $\begin{array}{c}\text { Williams Creek National Fish } \\
\text { Hatchery, AZ }\end{array}$ & CTM & 10 & 28.45 \\
\hline & $\begin{array}{c}\text { Williams Creek National Fish } \\
\text { Hatchery, AZ }\end{array}$ & CTM & 20 & 29.35 \\
\hline $\begin{array}{c}\text { Threader and } \\
\text { Houston (1983) }\end{array}$ & & UILT & 20 & 25.9 \\
\hline \multirow[t]{3}{*}{ Sonski (1984) } & Firehole River, MT & UILT & 15 & 27.4 \\
\hline & Firehole River, MT & UILT & 20 & 27.2 \\
\hline & Firehole River, MT & UILT & 23 & 26.3 \\
\hline
\end{tabular}




\begin{tabular}{|c|c|c|c|c|}
\hline & San Marcos State Fish Hatchery, TX & UILT & 15 & 27 \\
\hline & San Marcos State Fish Hatchery, TX & UILT & 20 & 26.8 \\
\hline & San Marcos State Fish Hatchery, TX & UILT & 23 & 27 \\
\hline Strange (1993) & Buffalo Springs Fish Hatchery, TN & CTM & 15 & 29.4 \\
\hline \multirow[t]{3}{*}{ Currie et al. (1998) } & Crystal Lake Fish Hatchery, MO & CTM & 10 & 28 \\
\hline & Crystal Lake Fish Hatchery, MO & CTM & 15 & 29.1 \\
\hline & Crystal Lake Fish Hatchery, MO & CTM & 20 & 29.8 \\
\hline \multirow[t]{12}{*}{$\begin{array}{c}\text { Myrick and Cech } \\
(2000)\end{array}$} & $\begin{array}{c}\text { Mt. Shasta State Fish Hatchery, CA } \\
\text { (Eagle Lake Strain) }\end{array}$ & CTM & 10 & 27.6 \\
\hline & $\begin{array}{l}\text { Mt. Shasta State Fish Hatchery, CA } \\
\text { (Eagle Lake Strain) }\end{array}$ & CTM & 14 & 28.6 \\
\hline & $\begin{array}{l}\text { Mt. Shasta State Fish Hatchery, CA } \\
\text { (Eagle Lake Strain) }\end{array}$ & CTM & 19 & 29.6 \\
\hline & $\begin{array}{l}\text { Mt. Shasta State Fish Hatchery, CA } \\
\text { (Eagle Lake Strain) }\end{array}$ & CTM & 19 & 30.6 \\
\hline & $\begin{array}{l}\text { Mt. Shasta State Fish Hatchery, CA } \\
\text { (Eagle Lake Strain) }\end{array}$ & CTM & 22 & 31 \\
\hline & $\begin{array}{l}\text { Mt. Shasta State Fish Hatchery, CA } \\
\text { (Eagle Lake Strain) }\end{array}$ & CTM & 25 & 32 \\
\hline & $\begin{array}{c}\text { Mt. Shasta State Fish Hatchery, CA } \\
\text { (Mt. Shasta Strain) }\end{array}$ & CTM & 10 & 27.7 \\
\hline & $\begin{array}{c}\text { Mt. Shasta State Fish Hatchery, CA } \\
\text { (Mt. Shasta Strain) }\end{array}$ & CTM & 14 & 28.4 \\
\hline & $\begin{array}{c}\text { Mt. Shasta State Fish Hatchery, CA } \\
\text { (Mt. Shasta Strain) }\end{array}$ & CTM & 19 & 29.3 \\
\hline & $\begin{array}{c}\text { Mt. Shasta State Fish Hatchery, CA } \\
\text { (Mt. Shasta Strain) }\end{array}$ & CTM & 19 & 30 \\
\hline & $\begin{array}{l}\text { Mt. Shasta State Fish Hatchery, CA } \\
\text { (Mt. Shasta Strain) }\end{array}$ & CTM & 22 & 30.7 \\
\hline & $\begin{array}{c}\text { Mt. Shasta State Fish Hatchery, CA } \\
\text { (Mt. Shasta Strain) }\end{array}$ & CTM & 25 & 31.5 \\
\hline \multirow[t]{2}{*}{$\begin{array}{c}\text { Carline and } \\
\text { Machung (2001) }\end{array}$} & Falling Spring, PA & CTM & 9.8 & 28.1 \\
\hline & Benner Springs Hatchery, PA & CTM & 9.8 & 27.6 \\
\hline \multirow[t]{3}{*}{$\begin{array}{c}\text { Myrick and Cech } \\
\text { (2005) }\end{array}$} & Nimbus State Fish Hatchery, CA & CTM & 11 & 27.5 \\
\hline & Nimbus State Fish Hatchery, CA & CTM & 15 & 28.4 \\
\hline & Nimbus State Fish Hatchery, CA & CTM & 19 & 29.6 \\
\hline Patra et al. (2007) & Gaden Trout Hatchery, Australia & CTM & 10 & 30.7 \\
\hline
\end{tabular}




\title{
Chapter 2: Comparing the Critical Thermal Maxima of Three Strains of Rainbow Trout
}

\begin{abstract}
Temperature has long been known to have numerous affects on trout physiology and survival. How these affects differ between different strains of the same species is not as well understood. To better understand the variation within and between populations we determined the critical thermal maxima (CTM) of three different strains of rainbow trout (Oncorhynchus mykiss). The three strains tested were the Case Western strain, the Kamloop strain, and the Wytheville strain. Mean total lengths ( \pm SEM) of the three strains were $94.63( \pm 0.81), 108.38( \pm 1.03)$, and $119.19( \pm 1.27) \mathrm{mm}$, respectively. This study found that the Case Western strain had the highest CTM of the three strains $\left(31.29^{\circ} \mathrm{C}\right)$, the Wytheville strain had the second highest $\left(31.20^{\circ} \mathrm{C}\right)$ and the Kamloop strain had the lowest CTM $\left(31.14^{\circ} \mathrm{C}\right)$. We found that the CTM of the Case Western strain was significantly higher compared to the Kamloop and Wytheville strains (Mann-Whitney $U ; p<0.003$ ). Linear regression results showed that condition factor $(K)$ also had a significant influence on CTM $(p<0.001)$. Analysis of Covariance further showed that both strain and $\mathrm{K}$ had a significant influence on CTM $(p<0.005)$, but there was no interaction between the two variables. Therefore, we conclude that the Case Western fish used in this study had a higher mean CTM than the other two strains and that $\mathrm{K}$ must be accounted for when determining CTM. This slightly higher thermal tolerance may allow this strain to persist longer in stocking or aquaculture settings where exposure to high temperatures is expected.

\section{Introduction}

Temperature is an influential variable on all poikilotherms. Temperature controls important processes like consumption, activity, metabolism and ultimately growth. Temperature can also have lethal consequences when temperatures exceed the tolerance of an individual or species (Wootton 1998). Fish rarely encounter these lethal temperatures in their natural environments because they have evolved to live in areas where they do not usually occur. However, due to the effects of climate change (Eaton and Scheller 1996) and other anthropogenic disturbances (Nelson and Palmer 2007), cold water species are expected to lose suitable habitat at an accelerated pace and encounter these lethal temperatures more often in the future. Therefore, it is important to fully understand the thermal tolerance of species that are likely to be affected by this habitat alteration. 
Rainbow trout (Oncorhynchus mykiss) and other salmonids are among those cold water species in danger of losing habitat due to the predicted warming of freshwaters (Eaton and Scheller 1996; Flebbe et al. 2006). This is significant not only because rainbow trout play critical roles in ecosystems as top predators, but because they are also among the most economically significant species in the world. Rainbow trout make up a substantial portion of recreational trout fisheries across the United States. They are also produced en masse by the aquaculture industry around the world (FAO 2005). Upwards of 95\% of all rainbow trout consumed in the United States are commercially produced (Ladewig and Morat 1995). For these reasons, identification of individuals or an entire strain of rainbow trout that tolerates what are generally considered stressful temperatures would be valuable for restoring trout populations to streams where suitable thermal habitat no longer exists. This information could also be valuable to the aquaculture industry where such a strain could expand the range of where rainbow trout can be cultured, or increase profits through longer growing seasons.

Past research has shown mixed results on whether or not thermal tolerance can differ between strains of the same species of trout. Wahl (1974) found significant differences in mean times to death among 6 strains of brook trout (Salvelinus fontinalis) exposed to $27.5^{\circ} \mathrm{C}$ water. These findings are significant because he showed through repetition of experiments and experiments between inbred and outbred strains that upper thermal tolerance is very likely determined genetically. The work done by Carline and Machung (2001) also suggests that thermal tolerance is genetically linked. They found that wild strains of brown (Salmo trutta), brook and rainbow trout had consistently higher critical thermal maximas (CTM) than domestic strains of the same species. More recently, Ineno et al. (2005) showed that through generations of selective breeding a rainbow trout strain developed a marginally higher thermal tolerance than two unselected strains. Collectively, this work strongly suggests a genetic basis for thermal tolerance and that it can differ between strains of the same species. However, other studies have shown contrasting results. Kaya (1978) found no significant difference in the thermal tolerance of 
rainbow trout inhabiting the Firehole River and two domestic stock strains. Myrick and Cech (2000) also found no difference in the CTMs of two different strains of rainbow trout at a variety of acclimation temperatures.

One strain of rainbow trout that reportedly tolerates high temperatures well is the Case Western strain. The strain was initially developed by Dr. Mitsuo Teraguchi at Case Western Reserve University in the 1980's. The strain originated from fish that survived exposure to near lethal temperatures and were then registered as broodstock. Since that time however, the strain has been sold to and maintained at Laurel Hill Trout Farm, Inc. in Pennsylvania (Ken Semmens, West Virginia University, personal communication). Individuals from this strain have recently been grown at a West Virginia University aquaculture site where they ate and grew better than other strains of rainbow trout throughout warm summer months (Dan Miller, West Virginia University, personal communication). However, no additional selective pressure for thermal tolerance has been put on the strain and no work has been done to quantify the thermal tolerance of this strain since they were sold. This led us to question what their true thermal tolerance is and if it differs from other common strains of rainbow trout. The two other strains of rainbow trout used in this study were the Kamloop strain and the Wytheville strain. The Kamloop strain was used because it is one of the most widely cultured and stocked strains of trout in the United States. The Wytheville strain was used because it is a widely stocked strain in the Mid-Atlantic and Appalachian regions (Kincaid et al. 2001).

The two main objectives of this study were to quantify the CTM of the Case Western strain and the two other stock strains to determine if CTMs differ between different strains of rainbow trout. We also wanted to investigate the individual variation in thermal tolerance within a strain. We hypothesized that the Case Western strain would have a higher mean CTM than the Wytheville and Kamloop strains. 


\title{
Materials and Methods
}

\author{
Fish Collection and Holding
}

Age-0 rainbow trout fingerlings were obtained from the following sources. Wytheville strain fingerlings were obtained from Bowden State Fish Hatchery, WV on April 27, 2011. Kamloop strain fingerlings were obtained from Albert Powell State Fish Hatchery, MD on May 4, 2011. Case Western strain fingerlings were obtained from Murley Branch Hatchery, MD on July 15, 2011. All fish were transported back to the Fish Ecophysiology Laboratory of WVU's Division of Forestry and Natural Resources (229 Percival Hall) and slowly acclimated to $14^{\circ} \mathrm{C}$ water. Each strain was acclimated in 1,100 liter tanks which were part of a larger $\sim 7,500$ liter recirculating system. During this holding period photoperiod was kept at 14 hours light: 10 hours dark and ammonia, nitrites, temperature, and dissolved oxygen were measured daily. Alkalinity, $\mathrm{pH}$, conductivity and hardness were tested once a week. These were measured to verify suitable water quality throughout the acclimation period.

\section{CTM Trials}

Approximately 100 fish from each strain were selected at random from the holding tanks and moved to a 450 liter tank to acclimate to $20^{\circ} \mathrm{C}$ for two weeks prior to undergoing CTM trials (Becker and Genoway 1979; Carline and Machung 2001; Kaya 1978; Lee and Rinne 1980). Water temperatures in the acclimation tank were lowered to $14^{\circ} \mathrm{C}$ before fish were transferred from the holding tanks.

Temperatures in the acclimation tanks were then raised $3^{\circ} \mathrm{C} /$ day until they reached the acclimation temperature of $20^{\circ} \mathrm{C}$. During this acclimation period fish were fed Silver Cup floating pellet (Murray, Utah) composed of $40 \%$ protein and $10 \%$ fat every other day, but fasted 48 hours prior to the beginning of the experiments. Photoperiod was kept at 14 hours light: 10 hours dark and the water quality parameters described above were tested to ensure suitable water quality conditions during the experiments. 
Seventy five liter plastic tubs were used as the test chamber for our CTM determinations. Each fish was confined to one half of the container by a mesh wall while the other half contained a heater and an air stone. We used a 1000 watt heater (Farm Innovators Model W-449, Plymouth, Indiana) to heat the water and the water was circulated and aerated by an air stone to ensure even heating and oxygen saturation. One individual fish was selected at random, netted from the acclimation tank and placed in the test chamber. A one hour acclimation period to the test chamber was given to each individual before the temperature trial began. Strange et al. (1993) found that stress brought on by minor handling such as that described in our study did not lower the CTM of test subjects in similar experiments. Thus, we do not expect handling to impact our CTM results.

After the fish had been allowed to acclimate to the test chamber, the temperature was raised from an initial $20^{\circ} \mathrm{C}$, to the point where each individual lost equilibrium and did not regain it. The temperature increase was done at a rate of $0.3^{\circ} \mathrm{C} / \mathrm{min}$ (Becker and Genoway 1979; Beitinger et al. 2000; Carline and Machung 2001; Currie et al. 1998; Myrick and Cech 2000; Selong et al. 2001). The temperature where each fish lost equilibrium and did not regain it was that individual's CTM. Once this point was reached the fish was removed from the water, the water temperature was recorded, and the fish was returned to $20^{\circ} \mathrm{C}$ water where it could recover. Once the fish had adequately recovered from the temperature trial, they were anesthetized in a bath of tricaine methanesulfonate (MS-222; 100 $\mathrm{mg} / \mathrm{L})$, total length was measured and wet weight was recorded. Water in each test chamber was changed between determinations to ensure that there were no effects from "fish-conditioned water" (McCauley 1968).

This procedure was repeated on 54 individuals of the Wytheville strain, 81 individuals of the Kamloop strain, and 105 individuals of the Case Western strain. Mean total lengths ( \pm SEM) were 94.63 ( \pm 0.81$), 108.38( \pm 1.03)$, and $119.19( \pm 1.27) \mathrm{mm}$ and mean wet weights $( \pm S E M)$ were $8.56( \pm 0.25), 10.88$ 
$( \pm 0.34)$, and $16.15( \pm 0.53) \mathrm{g}$ for the Case Western, Kamloop, and Wytheville strains respectively (Table

2.1). Wytheville strain individuals began acclimation on May 2, 2011 and underwent the CTM trials on May 16-18, 2011. Kamloop strain individuals began acclimation on June 7, 2011 and underwent the CTM trials on June 21-24, 2011. Case Western strain individuals began acclimation on July 25, 2011 and underwent the CTM trials on August 8-12, 2011. Differences in sample sizes were due to the need to identify sufficient individuals for growth experiments (see Chapter 3). We wanted to test individuals with high and low thermal tolerances in growth experiments; therefore we had to run CTM determinations until enough individuals were identified from the tails of the distributions. The determinations were run at different times due to differences in timing of strain availability and limited lab space.

Statistical Analysis

The CTM for each strain was the cumulative mean of all the individual CTMs from that strain. A condition factor $(\mathrm{K})$ for each individual was calculated using the equation

$$
\mathrm{K}=\left(\left(10^{5}\right) * \mathrm{~W}\right) /\left(\mathrm{L}^{3}\right)
$$

Where $\mathrm{W}=$ wet weight $(\mathrm{g})$ and $\mathrm{L}=$ total length $(\mathrm{mm}$; Ricker 1975). $\mathrm{K}$ along with total length and wet weight were then used to determine if any relationship exists between these variables and CTM. The normality of each strain's CTM distribution was assessed using quantile - quantile distribution plots. Because all CTM distribution curves were found to be non-normal, a Kruskal-Wallis test was used to test for any differences in CTM between strains. A Mann-Whitney $U$ test was then used to conduct pairwise comparisons between the CTMs of the three strains. The relationships between CTM and K, total length, and wet weight were assessed by fitting linear regression models to each relationship and then testing the slopes of these regression lines. Analysis of covariance (ANCOVA) was then used to 
determine if $\mathrm{K}$ affected all strains similarly. Significance levels for all tests were set at $\alpha \leq 0.05$ and all statistical analysis was completed with R statistical software (R Development Core Team 2010).

\section{Results}

Overall, 240 individual fish were tested in this study. The mean CTM for all fish combined was $31.22^{\circ} \mathrm{C}$. The mean $\mathrm{CTMs}$ of the three separate strains were very similar to this overall average. The Case Western strain was found to have a mean CTM of $31.29^{\circ} \mathrm{C}$, the Wytheville strain had a mean CTM of $31.20^{\circ} \mathrm{C}$, and the Kamloop strain was found to have a mean CTM of $31.14^{\circ} \mathrm{C}$ (Table 2.1). All three strains showed significant deviations from normality in their distributions of CTMs. Although the CTMs of the three strains were quite similar, our Kruskal-Wallis test results showed a significant difference between the CTM's of the three strains $(p<0.001)$. Mann-Whitney $U$ tests showed that the Case Western strain had a significantly higher CTM than the Kamloop $(p<0.001)$ and Wytheville strains $(p<$ 0.003), but there was no difference between the Kamloop and Wytheville CTMs $(p=0.52)$. In addition to this, $\mathrm{K}$ was found to have a significant effect on CTM (linear regression, $\mathrm{p}<0.001$ ). K was positively correlated with CTM among the 240 individuals tested (Figure 2.3). Conversely, neither total length nor wet weights alone were significantly correlated with CTM (Table 2.2; Figures 2.4 and 2.5). Case Western strain individuals had the highest mean CTM, and also had the highest mean $\mathrm{K}$. The Wytheville strain had the second highest mean CTM as well as $\mathrm{K}$, and the Kamloop strain had the lowest mean CTM as well as $\mathrm{K}$ (Table 2.1). ANCOVA results (Table 2.3) further showed that there was no significant interaction between $\mathrm{K}$ and strain $(\mathrm{p}=0.21)$, but that $\mathrm{K}$ and strain both significantly influenced CTM $(\mathrm{p}<$ 0.005 and $p<0.001$, respectively).

\section{Discussion}


In this study, we found that the Case Western strain did have a higher CTM than the Kamloop and Wytheville strains which did not differ from each other. This significant difference between strains of the same species is in agreement with Carline and Machung (2001) who also found significant differences in CTM between different strains of trout. In their study of wild versus domestic strains of trout they found that wild strains of brown, brook and rainbow trout all had significantly higher CTMs than their domestic counterparts. They suggested that the observed difference was either due to discrepancies in thermal histories or genetics. Wild populations likely experience a wider range of temperatures than hatchery fish, which would allow for some selection towards thermal tolerance. Vincent (1960) also found that wild brook trout outperformed domestic brook trout when exposed to high temperatures $\left(26.6^{\circ} \mathrm{C}\right)$. A study of Amargosa pupfish (Cyprinodon nevadensis) also supports this theory. Hirshfield and Soltz (1980) compared two distinct populations of Amargosa pupfish, one that inhabits a spring where temperatures are very stable $\left(27.3^{\circ} \mathrm{C}\right)$ and one that inhabits a river whose temperatures vary widely $\left(0-40^{\circ} \mathrm{C}\right)$. They found that the population inhabiting the spring tolerated a narrower range of temperatures than the population inhabiting the river. They attribute this difference to the fact that the populations have been isolated for an estimated 10,000 years and have diverged genetically.

In our study we used young fish from similar hatchery conditions and acclimation conditions for all three strains. Therefore, the difference we see in this study is not likely due to the age or thermal histories of the fish. Cox (1974) found a significant relationship between fish size and CTM. He found that larger bluegill (Lepomis macrochirus) lost equilibrium at lower temperatures than smaller fish of the same species. Benfey (1996) also found that younger brook trout were better able to survive stressful temperatures of than older individuals of the same species. However, we found that the observed difference in CTM was not related to differences in wet weight or total length, which is in agreement with Carline and Machung (2001). There seems to be no clear trend across species as to whether body 
size or age effects CTM. Ontogenic or physiologic differences among species may be the cause of this discrepancy. Surface area to volume ratio may also have an impact on this relationship. Smaller fish have larger surface area to volume ratios allow heat to penetrate their bodies more readily whereas larger fish may be able to persist slightly longer due to smaller surface area to volume ratios.

This study did, however document an influence of $K$ on the CTM on juvenile rainbow trout (Figure 2.3) which is contrary to results found by Carline and Machung (2001). ANCOVA results showed that $\mathrm{K}$ affected all strains similarly. As $\mathrm{K}$ increased so did CTM within each strain (Table 2.3). This suggests that the difference we observed between the CTMs of the strains is not confounded by the differences in $\mathrm{K}$. This relationship may have a simple explanation; we know that during rapidly increasing water temperatures the internal temperature of a fish can lag behind that of the surrounding environment (Dean 1973), and fat may exaggerate this discrepancy. Fat acts as an insulator and therefore may allow the fish's internal temperature to lag further behind that of the outside environment. The more fat a fish has, the higher its condition and the longer the lag time between internal temperature and the surrounding environmental temperature allowing it to persist longer in a stressful environment. Ruling out the above mentioned influences, genetic differences are likely responsible for the observed differences we see in this study.

More in-depth studies on the influence of genetics on thermal tolerance have brought more clarity to this topic recently. Perry et al. (2005) have shown that upper thermal tolerance is a heritable trait. Danzmann et al. (1999) and Jackson et al. (1998) have also identified three chromosomal regions in rainbow trout that have a strong influence on upper temperature tolerance. As they have all noted, this may allow for improvements in the selective breeding for this trait. It may also allow for those genes to be added to an existing strain's gene pool. As our study showed, there is variation in CTM among individuals of the same strain. Within a single strain we observed as much as a $1.7^{\circ} \mathrm{C}$ difference 
between the individuals with the highest thermal tolerances and the lowest (Figure 2.4). All this information may allow trout producers to select those individuals with high thermal tolerances, giving their strains of trout a marginally higher thermal tolerance. This information could be valuable in the future to the aquaculture and management processes as climate change threatens to diminish available cold water habitat (Eaton and Scheller 1996). This must be done with caution however, because it can quickly lead to outbreeding depression (Gharrett et al. 1999) or the loss of other important alleles from the gene pool by inadvertently selecting against them.

Work by Ineno et al. (2005) also suggests that thermal tolerance is likely genetically linked. Through selective breeding and rearing that selects for elevated thermal tolerance, they have created a strain of rainbow trout that performed marginally better in thermal tolerance trials when compared to an unselected strain. In using a test called the $\mathrm{LT}_{50}$ (similar to the UILT; see Chapter 1 ), they were able to find significant differences between the two strains, but they did not see significant differences in all tests. They did not detect any differences between the two strains when using the CTM method which employs a fast heating rate $\left(5^{\circ} \mathrm{C} /\right.$ hour in their study) and relatively short exposure times. This may suggest that the CTM method is not best suited for determining differences in thermal tolerances. Despite it being the cheapest most time effective method available, other tests that mimic natural conditions with slower heating rates and longer exposure times may be more apt in finding true differences. In a study looking at brook, rainbow and brown trout, Galbreath et al. (2004) found that with slower heating rates, they were able to detect differences between the thermal tolerances of trout that faster heating rates did not detect. CTM values represent temperatures that fish can survive for very short periods of time while tests like the $\mathrm{LT}_{50}$ give estimates of temperatures individuals can tolerate for extended periods of time (e.g. one week, Elliot and Elliot 1995). Selong et al. (2001) suggests that the acclimated chronic exposure (ACE) method gives far more accurate results in terms of getting an accurate estimate of fish survival as a function of different temperatures and exposure times. 
Our CTM results are also higher than those previously reported for rainbow trout. With an identical acclimation temperature heating rate and trial endpoint to our study, Currie et al. (1998) found the mean CTM of $\sim 40 \mathrm{~mm}$ juvenile rainbow trout to be $29.8^{\circ} \mathrm{C}$. The mean CTM values from our study are between 1.49 and $1.34^{\circ} \mathrm{C}$ higher than the value they determined. This difference could be due to the differences in the size or condition of fish used, photoperiods, acclimation periods, strains of fish used, or some combination of these parameters. The CTM values we obtained were similar to the results found by Myrick and Cech (2000) with Eagle Lake and Mt. Shasta strains of juvenile rainbow trout acclimated to $22^{\circ} \mathrm{C}\left(31\right.$ and $30.7^{\circ} \mathrm{C}$ respectively).

Ultimately, the difference between the CTMs of the Case Western and Kamloop strains was only $0.15^{\circ} \mathrm{C}$, and the difference between the Case Western and Wytheville strains was only $0.09^{\circ} \mathrm{C}$. The significant difference we detected is due in large part to our large sample size, and it would be difficult to consider this difference ecologically significant. But again, this slight difference may indicate that with longer exposure times and at less immediately lethal temperatures, we may see this slight difference exaggerated (Elliot and Elliot 1995; Galbreath et al. 2004) allowing this strain to perform better under the influence of stressful temperatures. Future work using a more chronic exposure to sub -lethal temperatures, simulating conditions fish will likely experience in a natural or aquaculture setting may give a better estimate of how these strains may differ from one another. 


\section{Literature Cited}

Becker, C. D. and R. G. Genoway. 1979. Evaluation of the critical thermal maximum for determining thermal tolerance of freshwater fish. Environmental Biology of Fishes 4(3): 245-256.

Beitinger, T. L., W. A. Bennett and R.W. McCauley. 2000. Temperature tolerances of North American freshwater fishes exposed to dynamic changes in temperature. Environmental Biology of Fishes 58(3): 237-275.

Benfey, T. J. 1996. Use of all-female and triploid salmonids for aquaculture in Canada. Bulletin of the Aquaculture Association of Canada 2: 6-8.

Carline, R.F. and J. F. Machung. 2001. Critical thermal maxima of wild and domestic strains of trout. Transactions of the American Fisheries Society 130: 1211-1216.

Cox, D. K. 1974. Effects of three heating rates on the critical thermal maximum of bluegill. pp. 158-163. In: J. W. Gibbons and R. R. Sharitz (ed.) Thermal Ecology, CONF-730505, Nat. Tech. Inf. Serv., Springfield, VA.

Currie, R. J., W. A. Bennett and T.L. Beitinger. 1998. Critical thermal minima and maxima of three freshwater game-fish species acclimated to constant temperatures. Environmental Biology of Fishes 51(2): 187-200.

Danzmann, R. G., T. R. Jackson and M. M. Ferguson. 1999. Epistasis in allelic expression at upper temperature tolerance QTL in rainbow trout. Aquaculture 173: 45-58.

Dean, J. M. 1973. The response of fish to a modified thermal environment. pp. 33-63. In: W. Chavin, (ed.), Responses of Fish to Environmental Changes, Charles C. Thomas Publisher, Springfield, Illinois.

Eaton, J. G. and R. M. Scheller. 1996. Effects of climate warming on fish thermal habitat in streams of the United States. Limnology and Oceanography 41(5): 1109-1115.

Elliot, J. M. and J. A. Elliot. 1995. The effect of the rate of temperature increase on the critical thermal maximum for parr of Atlantic salmon and brown trout. Journal of Fish Biology 47: 917-919.

FAO. (C) 2005-2011. Cultured Aquatic Species Information Programme. Oncorhynchus mykiss. http://www.fao.org/fishery/culturedspecies/Oncorhynchus_mykiss/en\#tcNA0126.

Flebbe, P. A., L. D. Roghair and J. L. Bruggink. 2006. Spatial modeling to project southern Appalachian trout distribution in a warmer climate. Transactions of the American Fisheries Society 135: 1371-1382.

Galbreath, P. F., N. D. Adams and T. H. Martin. 2004. Influence of heating rate on measurement of time to thermal maximum in trout. Aquaculture 241: 587-599.

Gharrett, A. J., W. W. Smoker, R. R. Reisenbichler and S. G. Taylor. 1999. Outbreeding depression in hybrids between odd- and even-broodyear pink salmon. Aquaculture 173: 117-129.

Hirshfield, M. F. and D. L. Soltz. 1980. Genetic differences in physiological tolerances of Amargosa pupfish (Cyprinodon nevadensis) populations. Science 207: 999-1001.

Ineno, T., S. Tsuchida, M. Kanda and S. Watabe. 2005. High temperature tolerance of rainbow trout Oncorhynchus mykiss selected by high temperature breeding. Fisheries Science 71: 767-775. 
Jackson, T. R., M. M. Ferguson, R. G. Danzmann, A. G. Fishback, P. E. Ihssen, M. O'Connell and T. J. Crease. 1998. Identification of two QTL influencing upper temperature tolerance in three rainbow trout (Oncorhynchus mykiss) half-sib families. Heredity 80: 143-151.

Kaya, C. M. 1978. Thermal resistance of rainbow trout from a permanently heated stream, and of two hatchery strains. The Progressive Fish-Culturist 40(4): 138-142.

Kincaid, H. L., L. J. Mengel and S. Brimm. 2001. National Fish Strain Registry - Trout, species tables of reported strains and broodstocks. United States Fish and Wildlife Service/United States Geological Survey, Washington DC. 165 pp.

Ladewig, K. F. and M. Morat. 1995. Rainbow Trout. Southern Regional Aquaculture Center Publication 224. $6 \mathrm{pp}$.

Lee, R. M. and J. N. Rinne. 1980. Critical thermal maxima of five trout species in the southwestern United States. Transactions of the American Fisheries Society 109(6): 632-635.

McCauley, R. W. 1968. Suggested physiological interactions among rainbow trout fingerlings undergoing thermal stress. Journal of the Fisheries Research Board of Canada 25: 1983-1986.

Myrick, C. A. and J. J. Cech Jr. 2000. Temperature influences on California rainbow trout physiological performance. Fish Physiology and Biochemistry 22(3): 245-254.

Nelson, K. C. and M. A. Palmer. 2007. Stream temperature surges under urbanization and climate change: data, models, and responses. Journal of the American Water Resources Association 43(2): 440-452.

Perry, G. M. L., C. M. Martyniuk, M. M. Ferguson and R. G. Danzmann. 2005. Genetic parameters for upper thermal tolerance and growth related traits in rainbow trout (Oncorhynchus mykiss). Aquaculture 250: 120-128.

R Development Core Team. 2010. R: A language and environment for statistical computing. $R$ Foundation for Statistical Computing, Vienna, Austria. ISBN 3-900051-07-0, URL http://www.Rproject.org.

Ricker, W. E. 1975. Computation and interpretation of biological statistics of fish populations. Bulletin of the Fisheries Research Board of Canada 191: 1-382.

Selong, J. H., T. E. McMahon, A.V. Zale and F.T. Barrows. 2001. Effect of temperature on growth and survival of bull trout, with application of an improved method for determining thermal tolerance in fishes. Transactions of the American Fisheries Society 130(6): 1026-1037.

Strange, R. J., R. B. Petrie and J.J. Cech. 1993. Slight stress does not lower critical thermal maximums in hatchery-reared rainbow trout. Folia Zoologica 42: 251-256.

Vincent, R. E. 1960. Some influences of domestication upon three stocks of brook trout (Salvelinus fontinalis Mitchill). Transactions of the American Fisheries Society 89(1): 35-52.

Wahl, R. W. 1974. Heat tolerance in strains of brook trout (Salvelinus fontinalis). Ph. D. Dissertation. The Pennsylvania State University. 90 pp.

Wootton, R.J. 1998. The ecology of teleost fishes. 2nd edition. Fish \& Fisheries Series, no. 24. Dordrecht: Kluwer. 
Table 2.1. Mean ( \pm SEM) critical thermal maxima (CTM), total length, wet weight and condition factor (K) of each strain. Different superscripted letters indicate statistical differences $(p \leq 0.05)$ in mean CTM.

\begin{tabular}{cccccc}
\hline Strain & $\mathrm{N}$ & $\mathrm{CTM}\left({ }^{\circ} \mathrm{C}\right)$ & Total Length $(\mathrm{mm})$ & Wet Weight $(\mathrm{g})$ & $\mathrm{K}$ \\
\hline Wytheville & 54 & $31.20 \pm 0.03^{\mathrm{A}}$ & $119.19 \pm 1.27$ & $16.15 \pm 0.53$ & $0.95 \pm 0.01$ \\
Kamloop & 81 & $31.14 \pm 0.03^{\mathrm{A}}$ & $108.38 \pm 1.03$ & $10.88 \pm 0.34$ & $0.86 \pm 0.01$ \\
Case Western & 105 & $31.29 \pm 0.02^{\mathrm{B}}$ & $94.63 \pm 0.81$ & $8.56 \pm 0.25$ & $1.01 \pm 0.01$ \\
\hline
\end{tabular}

Table 2.2. Summary of linear regression analysis relating CTM to length, wet weight and condition factor $(\mathrm{K})$. Superscripted ${ }^{*}$ indicates a significant relationship.

\begin{tabular}{cccccc}
\hline Variable & $\mathrm{N}$ & Slope & Intercept & $\mathrm{R}^{2}$ & $\mathrm{p}$-value \\
\hline Length & 240 & -0.0022 & 31.45 & 0.0126 & 0.0831 \\
Wet Weight & 240 & -0.0025 & 31.25 & 0.0017 & 0.5282 \\
K & 240 & 0.6089 & 30.56 & 0.0866 & $0.0000035^{*}$ \\
\hline
\end{tabular}

Table 2.3. Summary of ANCOVA results. Superscripted * indicates significance.

\begin{tabular}{cccc}
\hline Source & DF & F value & p-value \\
\hline Strain & 2 & 9.1278 & $0.00015^{*}$ \\
K & 1 & 8.2839 & $0.00437^{*}$ \\
Strain:K & 2 & 1.5951 & 0.20508 \\
\hline
\end{tabular}




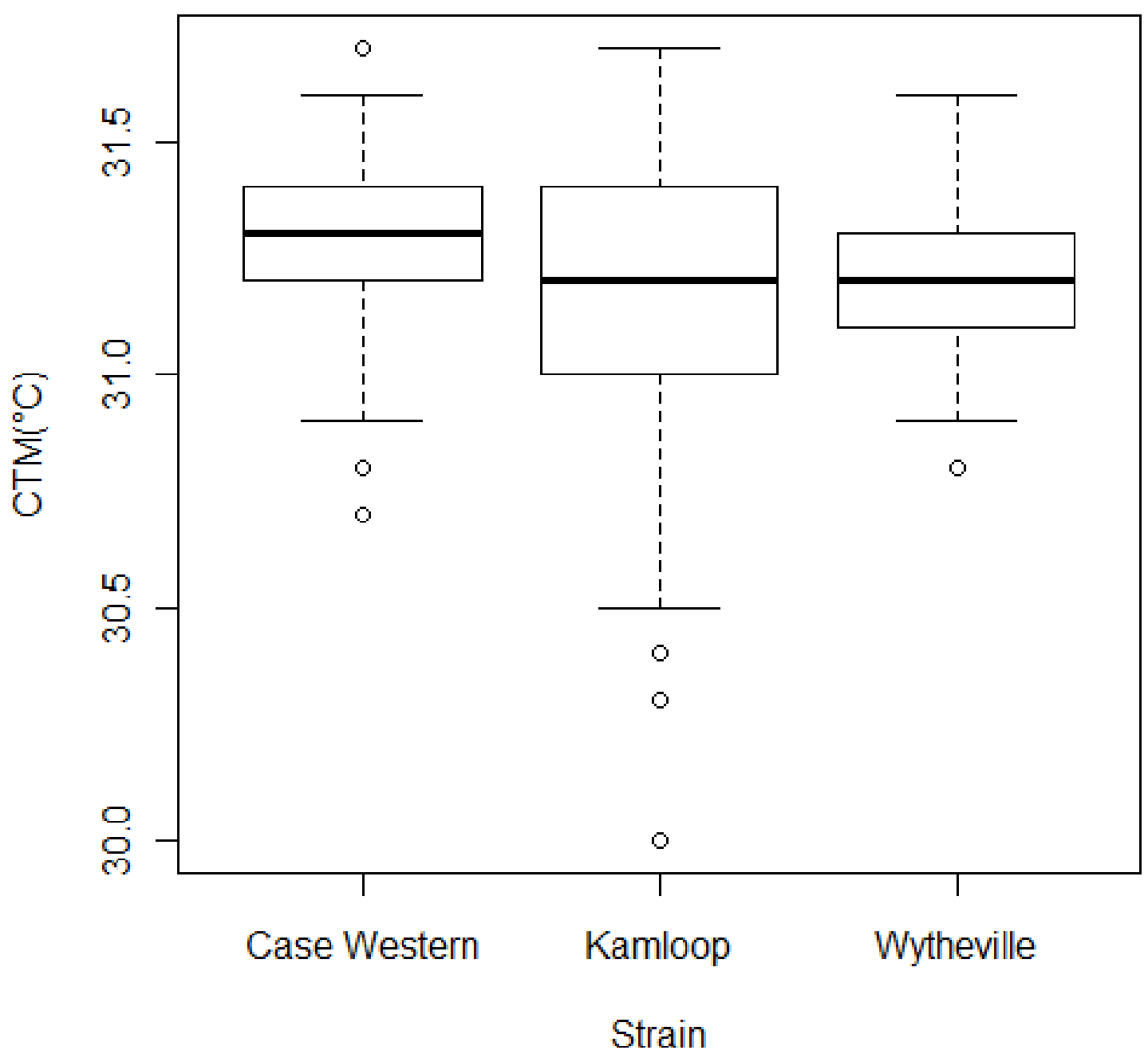

Figure 2.1. Boxplots depicting the distribution (lowest observation, lower quartile, median, upper quartile, and largest observation) of individual CTM observations for each strain of rainbow trout. Circles represent statistical outliers. 


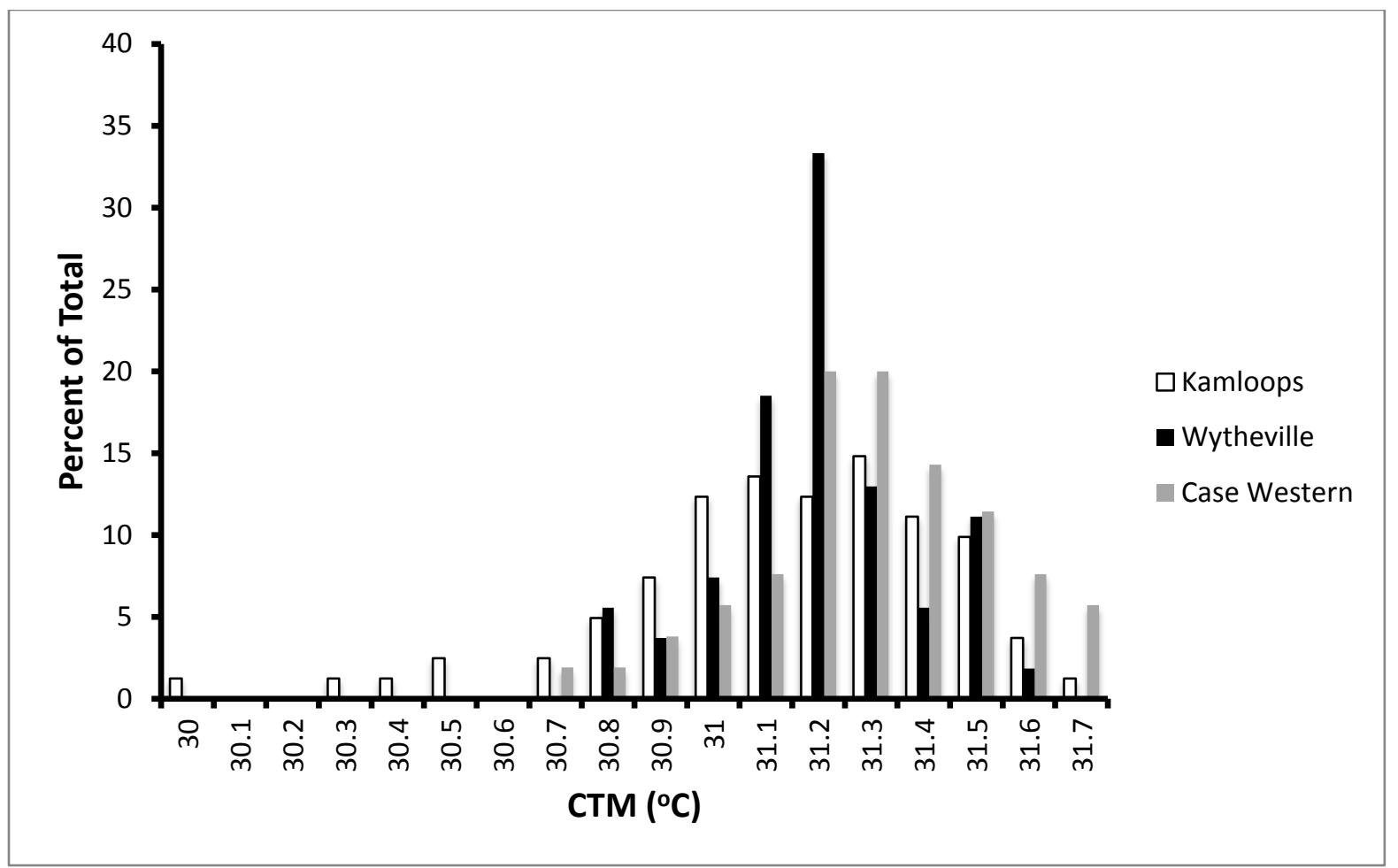

Fig. 2.2. Histogram showing the distribution of individual CTMs for each of the three strains. The frequency of CTM is shown as a percentage of the total to standardize distributions given differing sample sizes among strains. White bars represent individuals from the Kamloop strain, black bars represent individuals from the Wytheville strain, and gray bars represent individuals from the Case Western strain. 


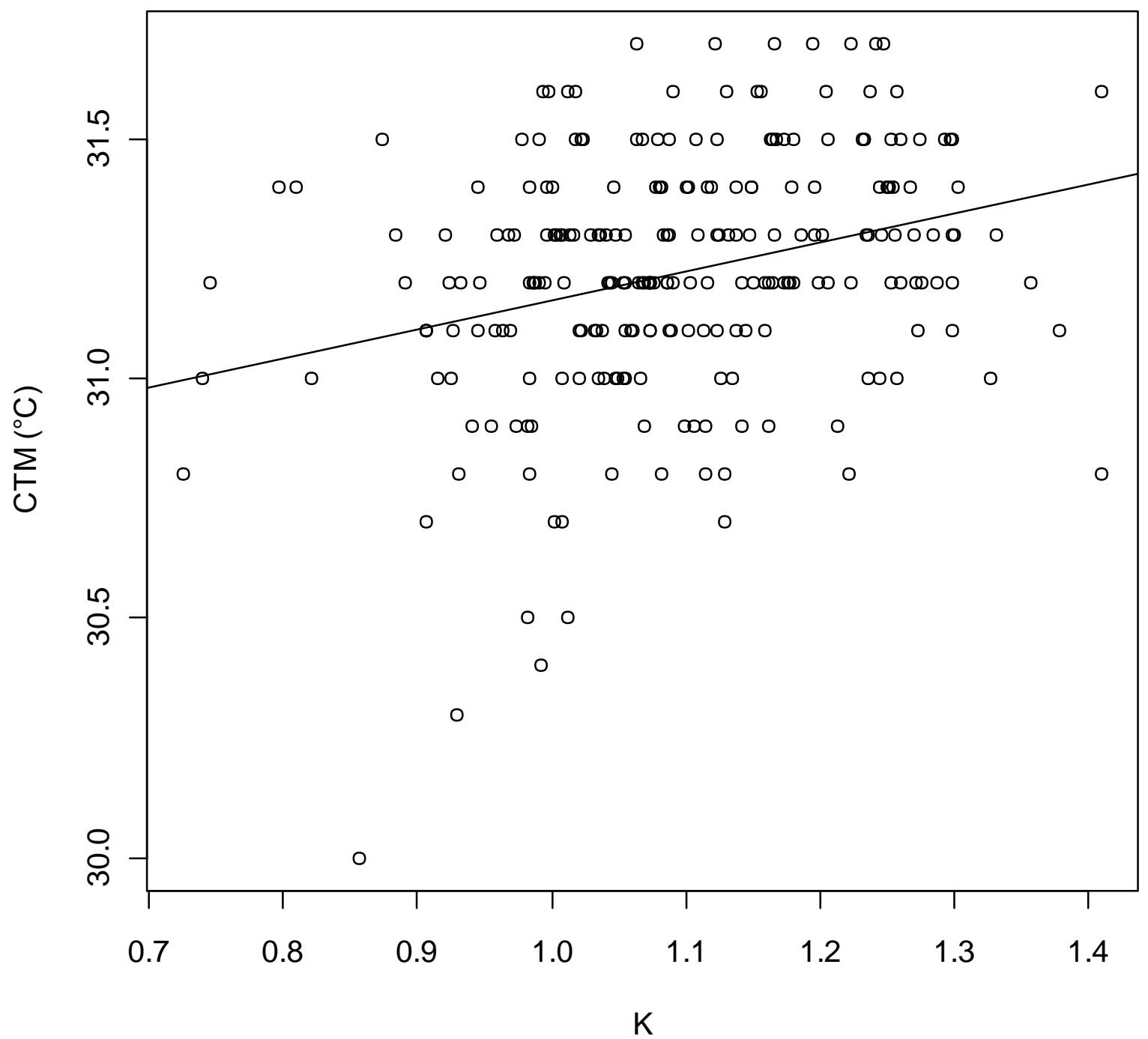

Figure 2.3. Scatterplot depicting the significant relationship of individual condition factors (K) vs. CTM ( $p$ $<0.001)$. 


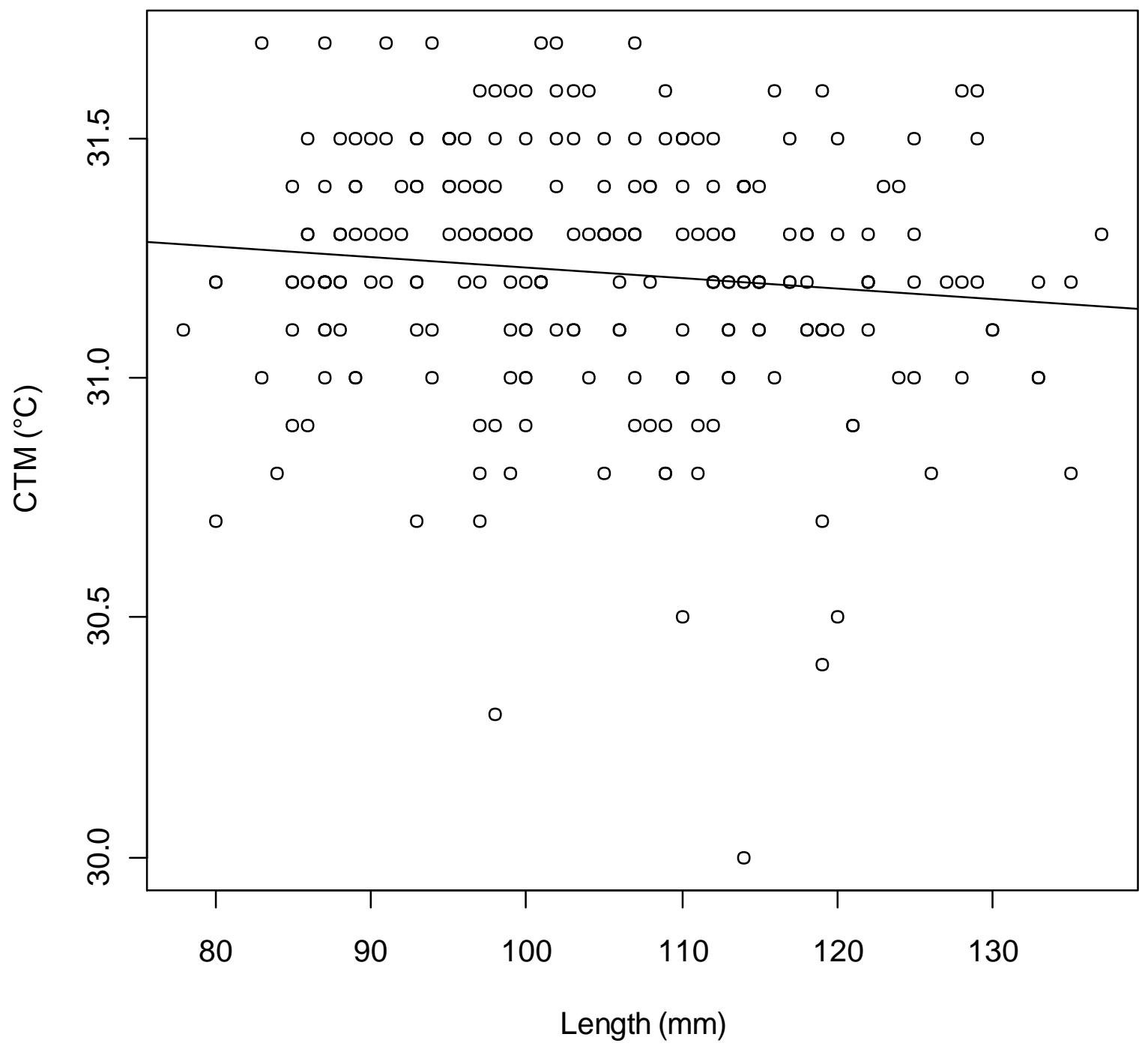

Figure 2.4. Scatterplot depicting the non-significant relationship between total length and CTM $(p=$ 0.08). 


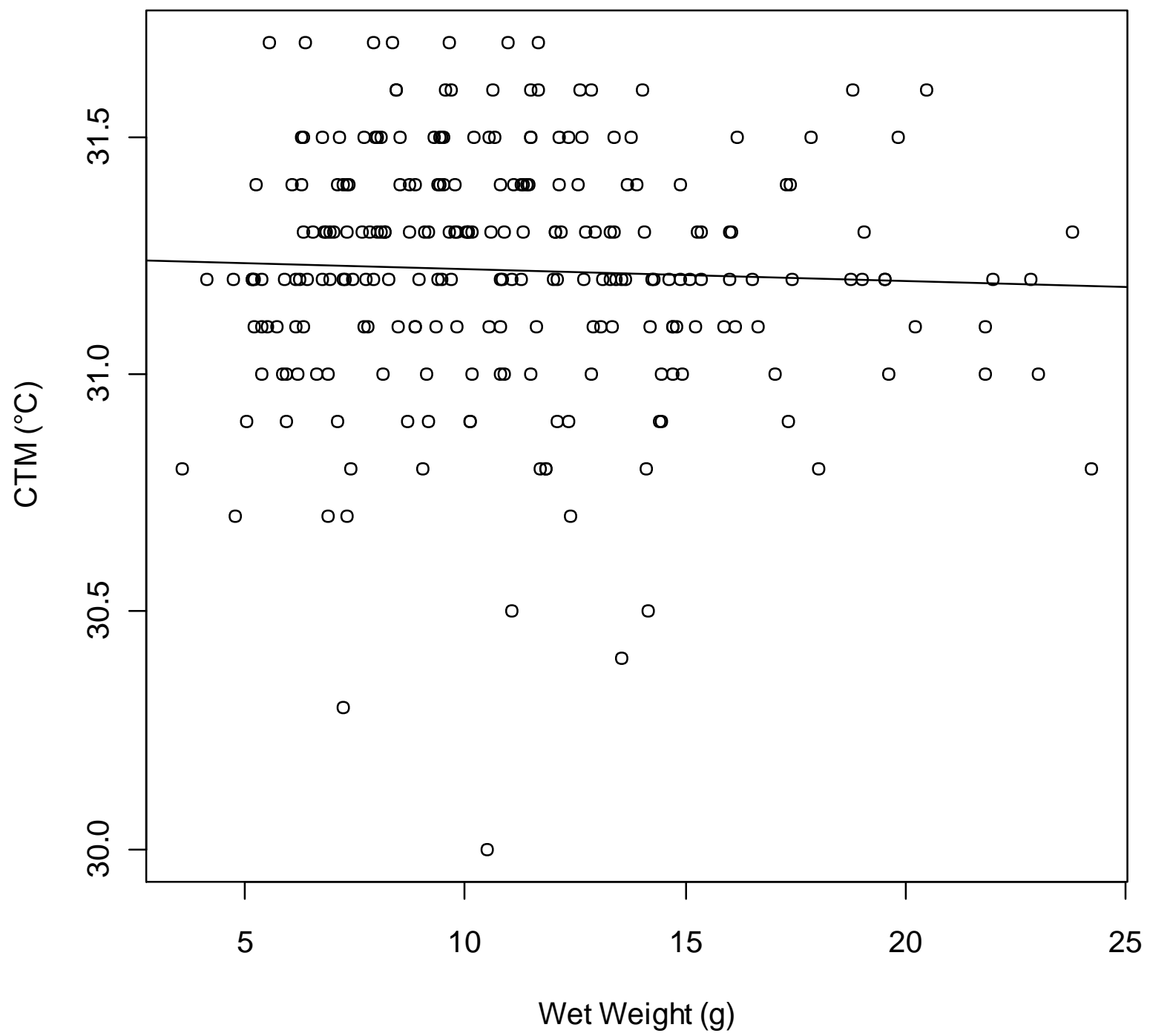

Figure 2.5. Scatterplot depicting the non-significant relationship between wet weight and CTM $(p=$ $0.53)$. 


\title{
Chapter 3: Consumption, Food Conversion Efficiency and Growth of Three Difference Strains of Rainbow Trout at Elevated Temperatures
}

\begin{abstract}
To better understand the relationship between thermal tolerance and growth at elevated temperatures in rainbow trout (Oncorhynchus mykiss) and how it may differ between strains, we determined consumption, food conversion efficiency (FCE) and growth rates for individuals whose critical thermal maxima (CTM) had previously been determined. Individuals who possessed the highest, lowest, and mean CTM were selected from each of the Case Western, Kamloop, and Wytheville strains and subjected to growth experiments at temperatures of 20 and $22^{\circ} \mathrm{C}$. We detected significant differences in the consumption, FCE and growth rates between the strains at each temperature (Twoway ANOVA; $p<0.001)$. At both temperatures the Case Western strain consistently had lower consumption, FCE and growth rates than the Kamloop and Wytheville strains. However, we found no significant correlation between CTM and consumption, FCE, or growth rates at either temperature though trends did exist. With increasing CTM, individual consumption, FCE and growth rates tended to decrease. This may indicate some tradeoff between CTM and growth rate, where individuals who have higher thermal tolerances do not grow as fast as individuals who have lower thermal tolerances.
\end{abstract}

\section{Introduction}

Many studies have documented the effects of different temperature regimes on the growth rates of rainbow trout (Oncorhynchus mykiss) (Bear 2005; Grabowski 1973; Hokanson et al. 1977; Myrick and Cech 1999; Myrick and Cech 2000; Myrick and Cech 2005; Railsback and Rose 1999; Sadler et al. 1986; Wurtsbaugh and Davis 1977). From these studies we know that rainbow trout growth rates follow a very predictable curve given the surrounding temperature. Growth rates increase with increasing water temperature to an optimum level, but decrease above this optimum temperature to zero (Railsback and Rose 1999; Figure 1). Due to this relationship, rainbow trout typically occur in areas where optimal temperatures for growth occur.

Despite this species trend, there is still much we do not know about how these temperature influences on growth vary within and between strains of the same species. There are a number of studies documenting differences in growth rates between strains of rainbow trout at a variety of 
temperatures (Ayles and Baker 1983; Klupp 1979; McKay et al. 1984; Myrick and Cech 2000; Overturf et al. 2003; Sadler et al. 1986), but few of these studies look at these differences at elevated or stressful temperatures. If stream temperatures rise across the United States as predicted (Eaton and Scheller 1996), trout are likely to encounter suboptimal growth temperatures more often as a result. It may be possible that at above optimal temperatures for growth, growth rates decline at different rates between stains. Lobon-Cervia and Rincon (1998) suggest this by showing that southern populations of brown trout (Salmo trutta) had slower decreases in growth rates above optimal growth temperatures than more northern populations studied extensively by Elliot et al. (1995). Another study that documented differences in growth rates at near lethal temperatures between strains was that of Myrick and Cech (2000). They found that Mt. Shasta strain rainbow trout had higher growth rates than Eagle Lake strain rainbow trout at 22 and $25^{\circ} \mathrm{C}$. Studies like these suggest that different strains of trout may differ in their performances at stressful temperatures which can in turn have important implications on management of these strains.

In our previous study (See Chapter 2) we looked at the thermal tolerance of rainbow trout and found that there were slight differences in the critical thermal maximas (CTMs) of three different strains. We also found that there was individual variation in CTM among and between the different strains. This study provided valuable information, but it also raised several questions. Will individuals with higher CTMs also grow better at higher temperatures? It stands to reason that if a fish can survive higher temperatures, it likely has a wider range of suitable temperatures for growth and survival when compared to an individual with a lower thermal tolerance. Therefore, at elevated or stressful temperatures like 20 or $22^{\circ} \mathrm{C}$ metabolic costs should be lower for an individual with a higher CTM, allowing it to grow faster than an individual with a lower CTM. This logic is echoed by Jobling (1981) who found that there were significant correlations between lethal temperatures, preferred temperatures, and growth optimums when looking at published literature for a number of species 
including rainbow trout. He found that as lethal temperatures increased, so did the optimal growth temperature for that species. An experimental study by Molony et al. (2004) found this to be true with a strain of rainbow trout that had indirectly been selected for growth, similar to the Case Western strain used in this study. They found that individuals from this selected line had higher thermal tolerances when compared to a natural strain, and also had higher growth rates though not specifically at elevated or stressful temperatures. Fish were exposed to periods of high temperatures but overall temperature was not held constant with temperatures ranging from $\sim 10$ to $\sim 25^{\circ} \mathrm{C}$ over the course of the growth experiment.

This study had two main objectives. We wanted to determine if significant differences exist between consumption, FCE, and growth rates of the Case Western, Kamloop and Wytheville strains at temperatures of 20 and $22^{\circ} \mathrm{C}$. We also wanted to determine if a significant relationship exists between CTM and consumption, food conversion efficiency (FCE) or growth rates in juvenile rainbow trout at temperatures of 20 and $22^{\circ} \mathrm{C}$. We expected to see higher mean consumption, FCE, and growth rates in the Case Western strain when compared to the other two strains due to the Case Western having a higher mean CTM. Regardless of strain, we hypothesized that individuals who had higher CTMs would also have higher consumption, FCE, and growth rates at stressful temperatures when compared to individuals with lower CTMs. Identifying potential differences between strains or individuals in these areas has important implications for the management and culture of rainbow trout in the face of climate change and rising water temperatures.

\section{Materials and Methods}

\section{Growth Experiments}

Individuals used in the growth experiments were selected based on their performance from those fish used in the CTM trials. From each strain, we selected the individuals having the highest, 
lowest, and mean CTMs. We selected 19 individuals from the Wytheville strain, 30 individuals from the Kamloop strain, and 29 individuals from the Case Western strain. These individuals were identified by a PIT (Passive Integrated Transponder) tag which was implanted in each fish after undergoing the CTM trials. All individuals selected for the growth experiments were tested at two different temperatures, 20 and $22^{\circ} \mathrm{C}$. We selected these temperatures because the literature has shown these temperatures to be above optimal for growth in rainbow trout (McCullough et al. 2001). Hokanson et al. (1977) and Myrick and Cech (2000) also showed that growth rates drop quickly to zero above these temperatures. Survival begins to drop off drastically above $22^{\circ} \mathrm{C}$ as well (Bear 2005).

Fish were randomly assigned to individual 37.85 liter aquaria with one fish in each aquarium. The test aquaria were part of a 1900 liter recirculating system that had a large collecting tank which contained filters to maintain water quality and heaters to control temperature fluctuations. Fresh water was pumped from this tank to each test aquaria at a rate of $\sim 2$ liters/minute and then returned back to the collecting tank. The sides of test tanks were covered with black plastic to minimize any effects of fish interaction. All fish were given an acclimation period of one week to each temperature. During this acclimation period the fish were fed $1 \%$ of their body weight every other day (Alsop and Wood 1997) but fasted 48 hours prior to the beginning of experiments. Fish in this experiment were kept on a photoperiod of 14 hours light: 10 hours dark. Ammonia, nitrites, temperature, and dissolved oxygen were measured daily and alkalinity, $\mathrm{pH}$, conductivity and hardness were tested once a week to ensure suitable water quality throughout the experiment (Table 3.1).

Immediately prior to the first feeding, each fish was anesthetized in a bath of tricaine methanesulfonate (MS-222; $100 \mathrm{mg} / \mathrm{L}$ ), measured and weighed to the nearest $0.01 \mathrm{~g}$. The same procedure was employed 36 hours after feeding had ceased to allow time for digestion and excretion of any food in the gut. Therefore, consumption was calculated over seven days while growth and FCE at 
each temperature were calculated over eight days. To maximize consumption, fish were fed ad libitum twice daily (Grayton and Beamish 1977) for seven days at each temperature. Feeding occurred once in the morning and once in the evening. Fish were fed Silver Cup floating pellets (Murray, Utah) that were composed of $40 \%$ protein and $10 \%$ fat. Pellets were counted and weighed prior to being offered to each fish. After one hour the uneaten food was collected and consumption in grams of food was calculated as

$$
C=(G / O)^{*} E
$$

Where $\mathrm{C}=$ Consumption, $\mathrm{G}=$ Grams of pellets offered, $\mathrm{O}=$ Number of pellets offered, and $\mathrm{E}=$ Number of pellets eaten. Consumption rate was then calculated as the total amount of food consumed (g)/mean weight of the fish (g)/day (d). Food conversion efficiency was calculated as total mass increased (g)/ total amount of food consumed (g)/ day (d). Growth rate was also calculated as the amount of mass gained (g)/ mean weight of the fish (g)/ day (d). All growth experiments were conducted between June and December 2011.

Statistical Analysis

The normality of all distributions was assessed using quantile - quantile distribution plots. Differences in consumption, FCE, and growth rates between strains within each temperature were tested using a two-way ANOVA (Galarowicz and Wahl 2003). Tukey's HSD tests were then used to conduct pairwise comparisons. Differences in consumption, FCE, and growth rates between temperatures within each strain were compared using a one-way ANOVA. Tukey's HSD tests were then used to conduct pairwise comparisons. The relationships between CTM and consumption, FCE, and growth rates among all fish at each temperature were assessed by fitting linear regression models to each relationship and then testing the slopes of these regression lines. The significance level for 
these tests was set at $\alpha \leq 0.05$ and all analysis was completed with $R$ statistical software (R Development Core Team 2010).

\section{Results}

Consumption, $\mathrm{FCE}$, and growth rates were determined for 76 fish at $20^{\circ} \mathrm{C}$ and 78 fish at $22^{\circ} \mathrm{C}$. Consumption, FCE, and growth rates are reported as the mean of all individual fish within each temperature within each strain. No distributions displayed significant deviations from normality when their quantiles were plotted. At $20^{\circ} \mathrm{C}$ initial mean total lengths ( \pm SEM) were $93.26( \pm 1.31), 111.77$ ( \pm 1.99$)$, and $130.40( \pm 3.07) \mathrm{mm}$ and initial mean wet weights $( \pm S E M)$ were $8.17( \pm 0.41), 11.69( \pm 0.59)$, and $20.92( \pm 1.95) \mathrm{g}$ for the Case Western, Kamloop, and Wytheville strains, respectively (Table 3.2). At $22^{\circ} \mathrm{C}$ initial mean total lengths $( \pm$ SEM) were $98.41( \pm 1.39), 117.97( \pm 2.04)$, and $129( \pm 3.07) \mathrm{mm}$ and initial mean wet weights $( \pm$ SEM) were $10.11( \pm 0.49), 15.48( \pm 0.77)$, and $20.15( \pm 1.32) \mathrm{g}$ for the Case Western, Kamloop, and Wytheville strains at respectively (Table 3.2). The mean consumption rate for all fish was $0.043 \mathrm{~g} / \mathrm{g} / \mathrm{d}$ at both 20 and $22^{\circ} \mathrm{C}$. The mean FCE for all individuals at each temperature was $0.150 \mathrm{~g} / \mathrm{g} / \mathrm{d}$ at $20^{\circ} \mathrm{C}$ and $0.139 \mathrm{~g} / \mathrm{g} / \mathrm{d}$ at $22^{\circ} \mathrm{C}$. The mean growth rate for all fish at each temperature was $0.044 \mathrm{~g} / \mathrm{g} / \mathrm{d}$ and $0.042 \mathrm{~g} / \mathrm{g} / \mathrm{d}\left(20\right.$ and $22^{\circ} \mathrm{C}$ respectively).

Overall, mean consumption by strain ranged from $0.039 \mathrm{~g} / \mathrm{g} / \mathrm{d}$ for the Case Western strain at 20 and $22^{\circ} \mathrm{C}$ to $0.048 \mathrm{~g} / \mathrm{g} / \mathrm{d}$ for the Wytheville strain at $20^{\circ} \mathrm{C}$ (Table 3.3 ). When comparing differences in consumption between temperatures within each strain we detected no significant differences. We did however detect significant differences between the consumption rates of the three strains at each temperature (Two-way ANOVA; $p<0.001$ ). We found that at $20^{\circ} \mathrm{C}$ the Kamloop strain had significantly higher mean consumption rate than the Wytheville and Case Western strains (Tukey's HSD; $p<0.03$ ). The Kamloop strain also had a significantly higher consumption rate than the Case Western strain at $22^{\circ} \mathrm{C}$ (Tukey's HSD; $p<0.002$ ) while the Wytheville strain did not differ from either. We did not detect 
any significant correlations between CTM and consumption at either temperature (Table 3.3). However, when all fish were plotted together we saw a negative trend at both temperatures (Figures 3.1 and 3.4). As individual CTM increased, feed consumption tended to decrease.

Mean FCEs ranged from $0.130 \mathrm{~g} / \mathrm{g} / \mathrm{d}$ for the Case Western strain at $22^{\circ} \mathrm{C}$ to $0.160 \mathrm{~g} / \mathrm{g} / \mathrm{d}$ for the Wytheville strain at $20^{\circ} \mathrm{C}$ (Table 3.3). When comparing differences in FCE between temperatures within each strain we detected two significant differences. Both the Wytheville and Case Western strains had higher FCEs at $20^{\circ} \mathrm{C}$ than at $22^{\circ} \mathrm{C}$ (One-way ANOVA; $p<0.05$ and $p<0.003$, respectively). The Kamloop strain also had higher FCE at $20^{\circ} \mathrm{C}$ though this was not significant. We also detected differences between the FCE of the strains within each temperature (Two-way ANOVA; $p<0.001$ ). At $20^{\circ} \mathrm{C}$, the Wytheville strain had a significantly higher mean FCE than the Case Western (Tukey's HSD; $p<0.03$ ), but the Kamloop strain did not differ from either. At $22^{\circ} \mathrm{C}$, the Case Western FCE was significantly lower than the Wytheville and Kamloop strains (Tukey's HSD; $p<0.005$ ) which did not differ significantly from each other. We also saw a general trend across both temperatures that as individual CTM increased, FCE decreased although this relationship was not significant (Figures 3.2 and 3.5).

Mean Growth rates ranged from $0.032 \mathrm{~g} / \mathrm{g} / \mathrm{d}$ for the Case Western strain at $22^{\circ} \mathrm{C}$ to $0.051 \mathrm{~g} / \mathrm{g} / \mathrm{d}$ for the Wytheville strain at $20^{\circ} \mathrm{C}$ (Table 3.3). Between temperatures within each strain, we detected no significant differences in growth rates. Although not significant, it was clear that each strain had higher growth rates at $20^{\circ} \mathrm{C}$ than they did at $22^{\circ} \mathrm{C}$. Significant differences did exist between the three strains at each temperature (Two-way ANOVA; $\mathrm{p}$ 0.001). At 20 and $22^{\circ} \mathrm{C}$, the Kamloop and Wytheville growth rates were both significantly higher than the Case Western's (Tukey's HSD; $p<0.02$ and $p<0.004$, respectively). The Wytheville and Kamloop growth rates did not differ from each other at either temperature. And again, we saw an overall trend with all fish at both temperatures that growth rates decreased with increasing CTM, though not significantly (Figures 3.3 and 3.6). The consumption, FCE 
and growth rate values for each strain at each temperature have been converted to common aquaculture measures and can be viewed in table 3.4 .

\section{Discussion}

This study of the consumption, FCE, and growth rates of three different strains of rainbow trout at elevated temperatures found several strain and temperature related differences. One difference we saw consistently was that the Case Western strain had lower consumption, FCE and growth rates than the Kamloop and Wytheville strains at both temperatures. We did not expect to see this however, because we found individuals from the Case Western strain to have a higher mean CTM than the other two strains (See Chapter 2). We expected that this increased thermal tolerance would also allow them to eat and grow more efficiently when compared to the other two strains at above optimal temperatures for growth. Despite this, we have shown different strains of the same species do differ in their abilities to perform at above optimal temperatures.

These results are in agreement with Myrick and Cech (2000) who also found that different strains of rainbow trout could differ in their abilities to grow at above optimal temperatures. They found that Mt. Shasta strain rainbow trout grew faster than Eagle Lake rainbows at temperatures of 22 and $25^{\circ} \mathrm{C}$. Imsland et al. (2001) also found that different strains of juvenile turbot (Scophthalmus maximus) differed in their growth rates at $22^{\circ} \mathrm{C}$, which is above their optimal growth temperatures (Imsland et al. 1996). Likewise, Lobon-Cervia and Rincon (1998) found that populations of brown trout in Spain displayed slower decreases in the slopes of their growth curves at above optimal temperatures when compared to more northerly populations studied in Britain. All three of these studies suggest that the observed differences in performance are likely due to countergradient variation/genetic differences. We feel that genetic disparities are likely the root of the differences observed between strains in this 
experiment as well because of the identical acclimation and test procedures and use of three unique strains of trout.

A difference in the initial size of test individuals (Table 3.2) was also considered as a possible factor affecting our results. In general, larger fish have lower specific metabolic and consumption rates when compared to smaller fish of the same species (Jobling 1983). This relationship causes comparisons between different sized individuals to be biased towards smaller fish having higher consumption and growth rates. In the analysis of our data, we used previously published allometric bioenergetics values for rainbow trout (Railsback and Rose 1999; Rand et al. 1993) to correct for any bias these differences in initial sizes may have had on our results. We found that using these corrected values had very little effect on our results. Using the corrected values only exaggerated the differences we had already observed with the uncorrected values. The corrected values inflated consumption and growth rates for the Wytheville strain, lowered the consumption and growth rates in the Case Western individuals and had little effect on the Kamloop's values. This caused the Case Western strain to appear to have performed even worse than what is observed with the uncorrected data. Therefore, all analysis and results in this chapter are presented using data that was not corrected for differences in initial. Analysis and results that were calculated using the size corrected data can be viewed in Appendix A.

When looking at the effects of temperature on each strain's consumption, FCE and growth rates, we detected two significant differences in FCE. We found that the mean FCE for the Wytheville and Case Western strains were significantly lower at $22^{\circ} \mathrm{C}$ than at $20^{\circ} \mathrm{C}$. Although not significant, we found all three strain's mean FCE and growth rates to be lower at $22^{\circ} \mathrm{C}$ as opposed to $20^{\circ} \mathrm{C}$. These trends are in agreement with the literature in that these temperatures are above rainbow trout's optimal growth temperatures (Bear 2005; Grabowski 1973; Hokanson et al 1977; Railsback and Rose 1999; Wurtsbaugh and Davis 1977) and they would continue to decrease as temperature rises. This decrease in FCE and 
growth can be explained by the fact that as temperature increases, so do the metabolic costs for trout. More energy must be expended on metabolism leaving less energy to be invested in growth.

Consumption rates changed very little within each strain between the two test temperatures. Past research has shown mixed results as to whether this should be expected. Myrick and Cech (2000) found that consumption increased over a range of temperatures from 10 to $19^{\circ} \mathrm{C}$ but decreased from 19 to $25^{\circ} \mathrm{C}$. They also found in another study that consumption increased from temperatures of 11 to $19^{\circ} \mathrm{C}$ (Myrick and Cech 1999). Conversely, Bear (2005) found no significant differences in consumption rates of rainbow trout over a range of temperatures from 8 to $20^{\circ} \mathrm{C}$ though there did appear to be a slight peak at temperatures of 14 and $16^{\circ} \mathrm{C}$. Again, consumption usually follows the same pattern as growth and metabolism. It rises with increasing temperatures to an optimum and then decreases above this optimum (Hartman and Hayward 2007). However, this decrease in consumption is thought to arise from stress brought on by unsuitable temperatures. The constant rates of consumption may be a good indication that the fish in these experiments were still comfortable at temperatures of 20 and $22^{\circ} \mathrm{C}$. Another explanation for the constant consumption rates is that we are observing their consumption rates on either side of their optimum. Temperatures of $20^{\circ} \mathrm{C}$ may be just below their optimum for consumption and temperatures of $22^{\circ} \mathrm{C}$ may be just above it. Data from Myrick and Cech (2000) also supports the idea that the optimum temperature for consumption in rainbow trout is between 19 and $22^{\circ} \mathrm{C}$.

We were also able to detect some trends in our correlations between individual CTM and consumption, FCE, and growth rates in juvenile rainbow trout. Though not statistically significant, we observed at both temperatures consumption, FCE and growth rate tended to decrease as individual CTM increased (Table 3.5; Fig 3.1 - 3.6). This negative relationship disagrees with our hypothesis that individuals with higher thermal tolerances would grow better at elevated temperatures when compared 
to individuals with lower thermal tolerances. This also disagrees with the findings of Jobling (1981). Though not significant, these negative correlations may indicate some trade-off between thermal tolerance and the ability to eat and grow above optimal temperatures. We know that genetically determined traits can be correlated (Bakker 1993; Pascual et al. 2004) and that selection for one may have a positive or negative affect on another trait. Henryon et al. (2002) showed that within a population of rainbow trout, there appeared to be a negative genetic correlation between growth rate and disease resistance to viral haemorrhagic septicaemia (VHS). By selecting for factors like length, weight or conversion efficiency in their trout, they unintentionally selected against VHS resistance. Similar phenomena can also be observed in other organisms. Brodie and Brodie (1999) showed that garter snakes (Thamnophis sirtalis) that are more resistant to a toxin produced by a key prey species are also slower. The selection for resistance to the toxin indirectly selects against the ability to move quickly. The results from our study may indicate a similar mechanism; that thermal tolerance is negatively genetically correlated with appetite, converting food efficiently and growing at warmer temperatures. Much more in depth studies on the genetics of these strains would be needed to verify this argument however.

As certain strains continue to get special attention as viable options to solve management problems (Bromage et al. 1992) or as those needing special management themselves (Arkush et al. 2002), studies like these will continue to be important. From this study we can see that the Case Western strain of rainbow trout did not eat, convert, or grow as well as the Kamloop or Wytheville strains at elevated temperatures. We also found that in general, fish that had higher CTMs did not perform as well above optimal temperatures as individuals whose thermal tolerance was lower. If extreme temperatures are a concern in stocking or culturing these strains, the Kamloop and Wytheville strains may have benefits over the Case Western strain. They have very similar CTMs to the Case 
Western strain (See Chapter 2) and individuals from these strains have higher consumption, FCE, and growth rates on average at stressful but sub-lethal temperatures. 


\section{Literature Cited}

Alsop, D. H. and C. M. Wood. 1997. The interactive effects of feeding and exercise on oxygen consumption, swimming performance and protein usage in juvenile rainbow trout (Oncorhynchus mykiss). The Journal of Experimental Biology 200: 2337-2346.

Arkush, K. D., A. R. Giese, H. L. Mendonca, A. M. McBride, G. D. Marty and P. W. Hedrick. 2002. Resistance to three pathogens in the endangered winter-run chinook salmon (Oncorhynchus tshawytscha): effects of inbreeding and major histocompatibility complex genotypes. Canadian Journal of Fisheries and Aquatic Sciences 59(6): 966-975.

Ayles, G. B. and R. F. Baker. 1983. Genetic differences in growth and survival between strains and hybrids of rainbow trout (Salmo gairdneri) stocked in aquaculture lakes in the Canadian prairies. Aquaculture 33: 269-280.

Bakker, T. C. M. 1993. Positive genetic correlation between female preference and preferred male ornament in sticklebacks. Nature 363: 255-257.

Bear, B. A. 2005. Effects of temperature on survival and growth of westslope cutthroat trout and rainbow trout: implications for conservation and restoration. Master's thesis. Montana State University. $68 \mathrm{pp}$.

Brodie, E. D., III, and E. D. Brodie, Jr. 1999. Costs of exploiting poisonous prey: evolutionary trade-offs in a predator-prey arms race. Evolution 53: 626-631.

Bromage. N., J. Jones, C. Randall, M. Thrush, B. Davies, J. Springate, J. Duston and G. Barker. 1992. Broodstock management, fecundity, egg quality and the timing of egg production in the rainbow trout (Oncorhynchus mykiss). Aquaculture 100: 141-166.

Eaton, J. G. and R. M. Scheller. 1996. Effects of climate warming on fish thermal habitat in streams of the United States. Limnology and Oceanography 41(5): 1109-1115.

Elliott, J. M., M. A. Hurley, and R. J. Fryer. 1995. A new, improved growth model for brown trout Salmo trutta. Functional Ecology 9:290-298.

Galarowicz, T. L. and D. H. Wahl. 2003. Differences in growth, consumption, and metabolism among walleyes from different latitudes. Transactions of the American Fisheries Society 132(3):425437.

Grabowski, S. J. 1973. Effects of fluctuating and constant temperatures on some hematological characteristics, tissue glycogen levels, and growth of steelhead trout (Salmo gairdneri). Ph. D. dissertation. University of Idaho. 77 pp.

Grayton, B. D. and F. W. H. Beamish. 1977. Effects of feeding frequency on food intake, growth and body composition of rainbow trout (Salmo gairdneri). Aquaculture 11(2): 159-172.

Hartman, K. J. and R. S. Hayward. 2007. Bioenergetics. Pages 515-560 in C. S. Guy and M. L. Brown, editors. Analysis and interpretation of freshwater fisheries data. American Fisheries Society, Bethesda, Maryland.

Henryon, M., A. Jokumsen, P. Berg, I. Lund, P. B. Pedersen, N. J. Olesen, W. J. Slierendrecht. 2002. Genetic variation for growth rate, feed conversion efficiency, and disease resistance exists within a farmed population of rainbow trout. Aquaculture 209: 59-76. 
Hokanson, K. E. F., C. F. Kleiner and T.W. Thorslund. 1977. Effects of constant temperatures and diel temperature fluctuations on specific growth and mortality rates and yield of juvenile rainbow trout, Salmo gairdneri. Journal of the Fisheries Research Board of Canada 34: 639-648.

Imsland, A. K., A. Foss and S. O. Stefansson. 2001. Variation in food intake, food conversion efficiency and growth of juvenile turbot from different geographic strains. Journal of Fish Biology 59: 449454.

Imsland, A. K., L. M. Sunde, A. Folkvord and S. O. Stefansson. 1996. The interaction of temperature and fish size on growth of juvenile turbot. Journal of Fish Biology 49: 926-940.

Jobling, M. 1981. Temperature tolerance and the final preferendum - rapid methods for assessment of optimum growth temperatures. Journal of Fish Biology 19: 439-455.

Jobling, M. 1983. Growth studies with fish - overcoming the problems of size variation. Journal of Fish Biology 22: 153-157.

Klupp, R. 1979. Genetic variance for growth in rainbow trout (Salmo gairdneri). Aquaculture 18(2): 123134.

Lobon-Cervia, J. and P. A. Rincon. 1998. Field assessment of the influence of temperature on growth rate in a brown trout population. Transactions of the American Fisheries Society 127:718-728.

McCullough, D. A., S. Spalding, D. Sturdevant and M. Hicks. 2001. Issue Paper 5: Summary of technical literature examining the physiological effects of temperature on salmonids. U.S. Environmental Protection Agency EPA 910-D-01-005.

McKay, L. R., G. W. Friars and P. E. Ihssen. 1984. Genotype x Temperature interactions for growth of rainbow trout. Aquaculture 41: 131-140.

Molony, B. W., A. R. Church, and G. B. Maguire. 2004. A comparison of the heat tolerance and growth of a selected and non-selected line of rainbow trout, Oncorhynchus mykiss, in Western Australia. Aquaculture: 655-665.

Myrick, C. A. and J. J. Cech Jr. 1999. Effects of ration size and temperature on the bioenergetics of juvenile California steelhead, Oncorhynchus mykiss.

Myrick, C. A. and J. J. Cech Jr. 2000. Temperature influences on California rainbow trout physiological performance. Fish Physiology and Biochemistry 22(3): 245-254.

Myrick, C. A. and J. J. Cech Jr. 2005. Effects of temperature on the growth, food consumption, and thermal tolerance of age-0 Nimbus-strain steelhead. North American Journal of Aquaculture 67:324-330.

Overturf, K., M. T. Casten, S. L. LaPatra, C. Rexroad III and R. W. Hardy. 2003. Comparison of growth performance, immunological response and genetic diversity of five strains of rainbow trout (Oncorhynchus mykiss). Aquaculture 217: 93-106.

Pascual, C., L. Arena, G. Cuzon, G. Gaxiola, G. Taboada, M. Valenzuela, C. Rosas. 2004. Effect of a sizebased selection program on blood metabolites and immune response of Litopenaeus vannamei juveniles fed different dietary carbohydrate levels. Aquaculture 230: 405-416.

R Development Core Team. 2010. R: A language and environment for statistical computing. $R$ Foundation for Statistical Computing, Vienna, Austria. ISBN 3-900051-07-0, URL http://www.Rproject.org.

Railsback, S. F. and K. A. Rose. 1999. Bioenergetics modeling of stream trout growth: temperature and food consumption effects. Transactions of the American Fisheries Society 128(2): 241-256. 
Rand, P. S., D. J. Stewart, P. W. Seelbach, M. L. Jones, and L. R. Wedge. 1993. Modeling steelhead population energetics in Lake Michigan and Ontario. Transactions of the American Fisheries Society 122: 977-1001.

Sadler, S. E., G. W. Friars, and P. E. Ihssen. 1986. The influence of temperature and genotype on the growth rate of hatchery-reared salmonids. Canadian Journal of Animal Sciences 66: 599-606. Wurtsbaugh, W. A. and G. E. Davis. 1977. Effects of temperature and ration level on the growth and food conversion efficiency of Salmo gairdneri, Richardson. Journal of Fish Biology 11(2): 87-98. 
Table 3.1. Summary of water quality measurements taken over the course of all growth experiments.

\begin{tabular}{cccccccc}
\hline $\begin{array}{c}\text { Temperature } \\
(\text { Range })\end{array}$ & $\begin{array}{c}\text { Ammonia } \\
(\mathrm{mg} / \mathrm{l})\end{array}$ & $\begin{array}{c}\text { Nitrites } \\
(\mathrm{mg} / \mathrm{l})\end{array}$ & $\begin{array}{c}\text { Dissolved } \\
\text { Oxygen }(\mathrm{mg} / \mathrm{l})\end{array}$ & $\begin{array}{c}\text { Alkalinity } \\
(\mathrm{mg} / \mathrm{l} \\
\left.\mathrm{CaCO}_{3}\right)\end{array}$ & $\begin{array}{c}\text { Hardness } \\
(\mathrm{mg} / \mathrm{l} \mathrm{Ca})\end{array}$ & $\begin{array}{c}\text { Conductivity } \\
(\mu \mathrm{S} / \mathrm{cm})\end{array}$ & $\mathrm{pH}$ \\
\hline $\begin{array}{c}19.9-20.1^{\circ} \mathrm{C} \\
21.9-22.1^{\circ} \mathrm{C}\end{array}$ & $<0.14$ & $<0.037$ & $>8.33$ & $54-76$ & $140-160$ & $540-615$ & $6.89-7.66$ \\
\hline
\end{tabular}

Table 3.2. Mean $( \pm S E M)$ initial lengths and weights of fish used in growth experiments.

\begin{tabular}{cccc}
\hline Temperature & Strain & Total Length $(\mathrm{mm})$ & Wet Weight $(\mathrm{g})$ \\
\hline $20^{\circ} \mathrm{C}$ & Wytheville & $130.53 \pm 3.07$ & $20.92 \pm 1.95$ \\
& Kamloop & $111.77 \pm 1.99$ & $11.69 \pm 0.59$ \\
& Case Western & $93.26 \pm 1.31$ & $8.17 \pm 0.41$ \\
\hline $22^{\circ} \mathrm{C}$ & Wytheville & $129.00 \pm 3.07$ & $20.15 \pm 1.32$ \\
& Kamloop & $117.97 \pm 2.04$ & $15.48 \pm 0.77$ \\
& Case Western & $98.41 \pm 1.39$ & $10.11 \pm 0.49$ \\
\hline
\end{tabular}

Table 3.3. Mean ( \pm SEM) consumption, food conversion efficiency $(F C E)$ and growth rates of each strain at each test temperature. Statistical differences between strains within a temperature are denoted by different superscripted letters. Statistical differences between temperatures within a strain are denoted by *.

\begin{tabular}{cccccc}
\hline Temperature & Strain & $\mathrm{N}$ & Consumption $(\mathrm{g} / \mathrm{g} / \mathrm{d})$ & $\mathrm{FCE}(\mathrm{g} / \mathrm{g} / \mathrm{d})$ & Growth Rate $(\mathrm{g} / \mathrm{g} / \mathrm{d})$ \\
\hline $20^{\circ} \mathrm{C}$ & Wytheville & 19 & $0.042 \pm 0.002^{\mathrm{B}}$ & $0.160 \pm 0.004^{\mathrm{A} *}$ & $0.046 \pm 0.002^{\mathrm{A}}$ \\
& Kamloop & 30 & $0.048 \pm 0.002^{\mathrm{A}}$ & $0.150 \pm 0.004^{\mathrm{AB}}$ & $0.048 \pm 0.001^{\mathrm{A}}$ \\
& Case Western & 27 & $0.039 \pm 0.001^{\mathrm{B}}$ & $0.144 \pm 0.004^{\mathrm{B} *}$ & $0.039 \pm 0.002^{\mathrm{B}}$ \\
\hline $22^{\circ} \mathrm{C}$ & Wytheville & 19 & $0.043 \pm 0.002^{\mathrm{AB}}$ & $0.148 \pm 0.004^{\mathrm{A} *}$ & $0.045 \pm 0.002^{\mathrm{A}}$ \\
& Kamloop & 30 & $0.046 \pm 0.001^{\mathrm{A}}$ & $0.142 \pm 0.003^{\mathrm{A}}$ & $0.046 \pm 0.001^{\mathrm{A}}$ \\
& Case Western & 29 & $0.039 \pm 0.002^{\mathrm{B}}$ & $0.130 \pm 0.003^{\mathrm{B} *}$ & $0.036 \pm 0.002^{\mathrm{B}}$ \\
\hline
\end{tabular}


Table 3.4. Mean $( \pm S E M)$ consumption, food conversion ratio $(F C R)$ and growth rates of each strain at each test temperature in common aquaculture measures.

\begin{tabular}{cccccc}
\hline Temperature & Strain & $\mathrm{N}$ & $\begin{array}{c}\text { Consumption (\% } \\
\text { body weight/day) }\end{array}$ & $\begin{array}{c}\text { FCR (Ibs growth/lbs } \\
\text { fed) }\end{array}$ & $\begin{array}{c}\text { Growth Rate } \\
\text { (mm/day) }\end{array}$ \\
\hline $20^{\circ} \mathrm{C}$ & Wytheville & 19 & $4.19 \pm 0.19$ & $1.28 \pm 0.03$ & $1.10 \pm 0.08$ \\
& Kamloop & 30 & $4.81 \pm 0.16$ & $1.16 \pm 0.03$ & $0.77 \pm 0.04$ \\
& Case Western & 27 & $3.93 \pm 0.14$ & $1.13 \pm 0.03$ & $0.76 \pm 0.05$ \\
\hline $22{ }^{\circ} \mathrm{C}$ & Wytheville & 19 & $4.29 \pm 0.17$ & $1.19 \pm 0.03$ & $0.99 \pm 0.08$ \\
& Kamloop & 30 & $4.60 \pm 0.12$ & $1.14 \pm 0.02$ & $0.93 \pm 0.06$ \\
& Case Western & 29 & $3.87 \pm 0.15$ & $1.04 \pm 0.02$ & $0.75 \pm 0.05$ \\
\hline
\end{tabular}

Table 3.5. Summary of linear regression analysis relating CTM to consumption, FCE and growth at 20 and $22^{\circ} \mathrm{C}$.

\begin{tabular}{ccccccc}
\hline Temperature & Variable & $\mathrm{N}$ & Slope & Intercept & $\mathrm{R}^{2}$ & $\mathrm{p}$-value \\
\hline $20^{\circ} \mathrm{C}$ & Consumption & 76 & -0.0007 & 0.0655 & 0.0006 & 0.8278 \\
& $\mathrm{FCE}$ & 76 & -0.0091 & 0.4348 & 0.0212 & 0.2096 \\
& Growth & 76 & -0.0034 & 0.1495 & 0.0142 & 0.3057 \\
\hline $22^{\circ} \mathrm{C}$ & Consumption & 78 & -0.0048 & 0.1927 & 0.0342 & 0.1050 \\
& FCE & 78 & -0.0060 & 0.3265 & 0.0126 & 0.3282 \\
& Growth & 78 & -0.0061 & 0.2328 & 0.0348 & 0.1018 \\
\hline
\end{tabular}




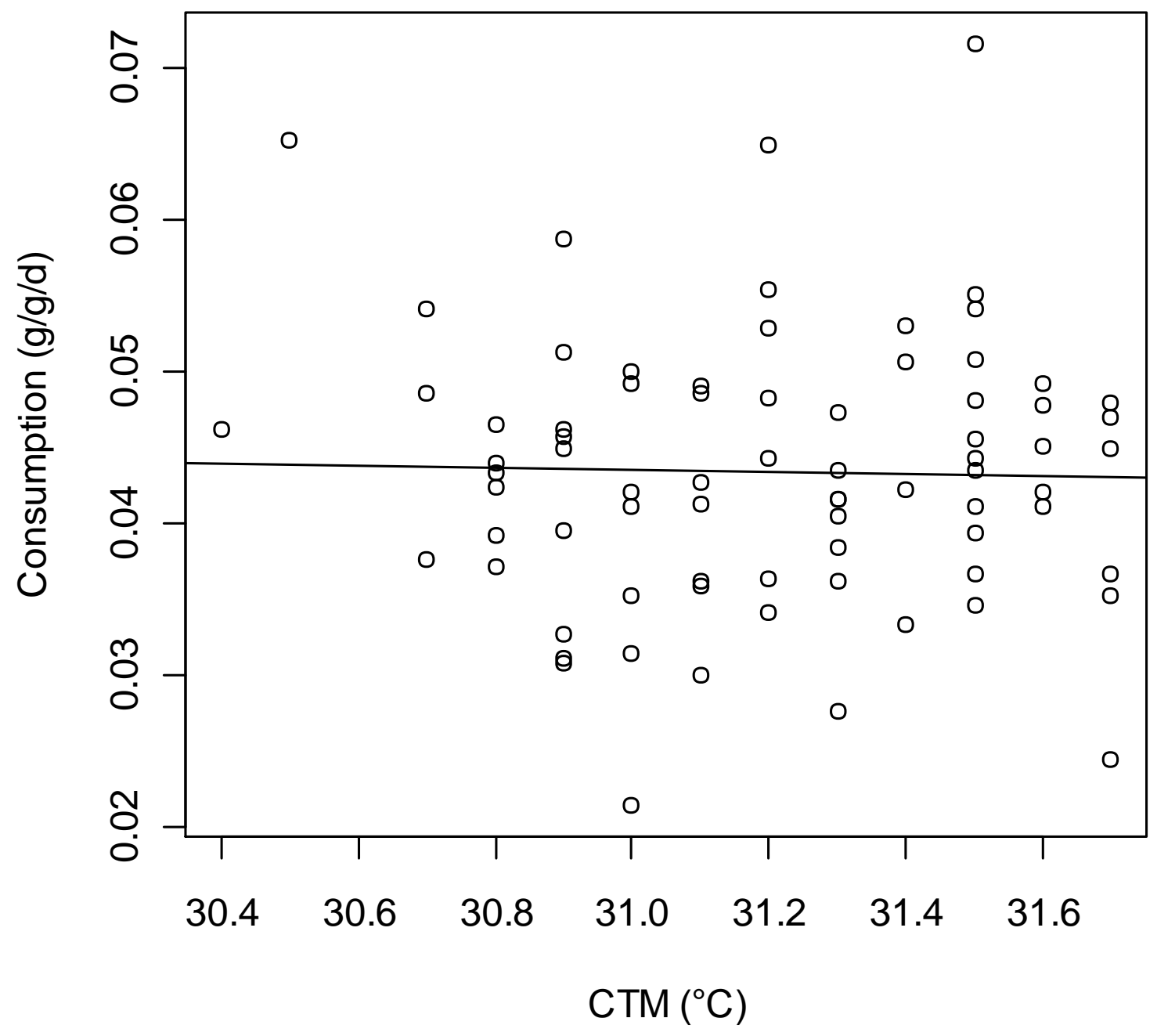

Figure 3.1. Scatter plot depicting the negative correlation between CTM and consumption among all individuals tested at $20^{\circ} \mathrm{C}$. This relationship was not significant $(p=0.82)$. 


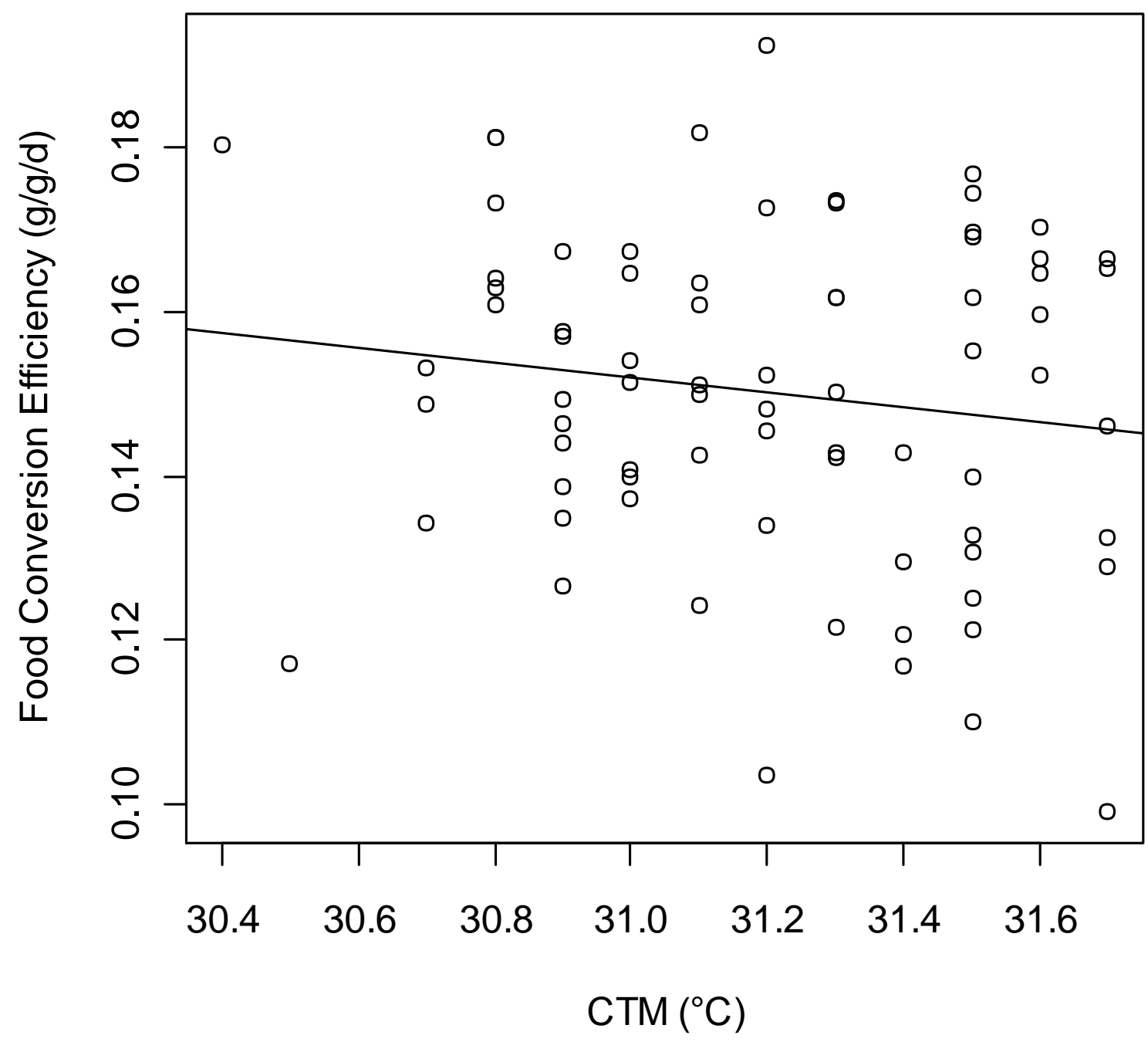

Figure 3.2. Scatter plot depicting the negative correlation between CTM and FCE among all individuals tested at $20^{\circ} \mathrm{C}$. This relationship was not significant $(p=0.21)$. 


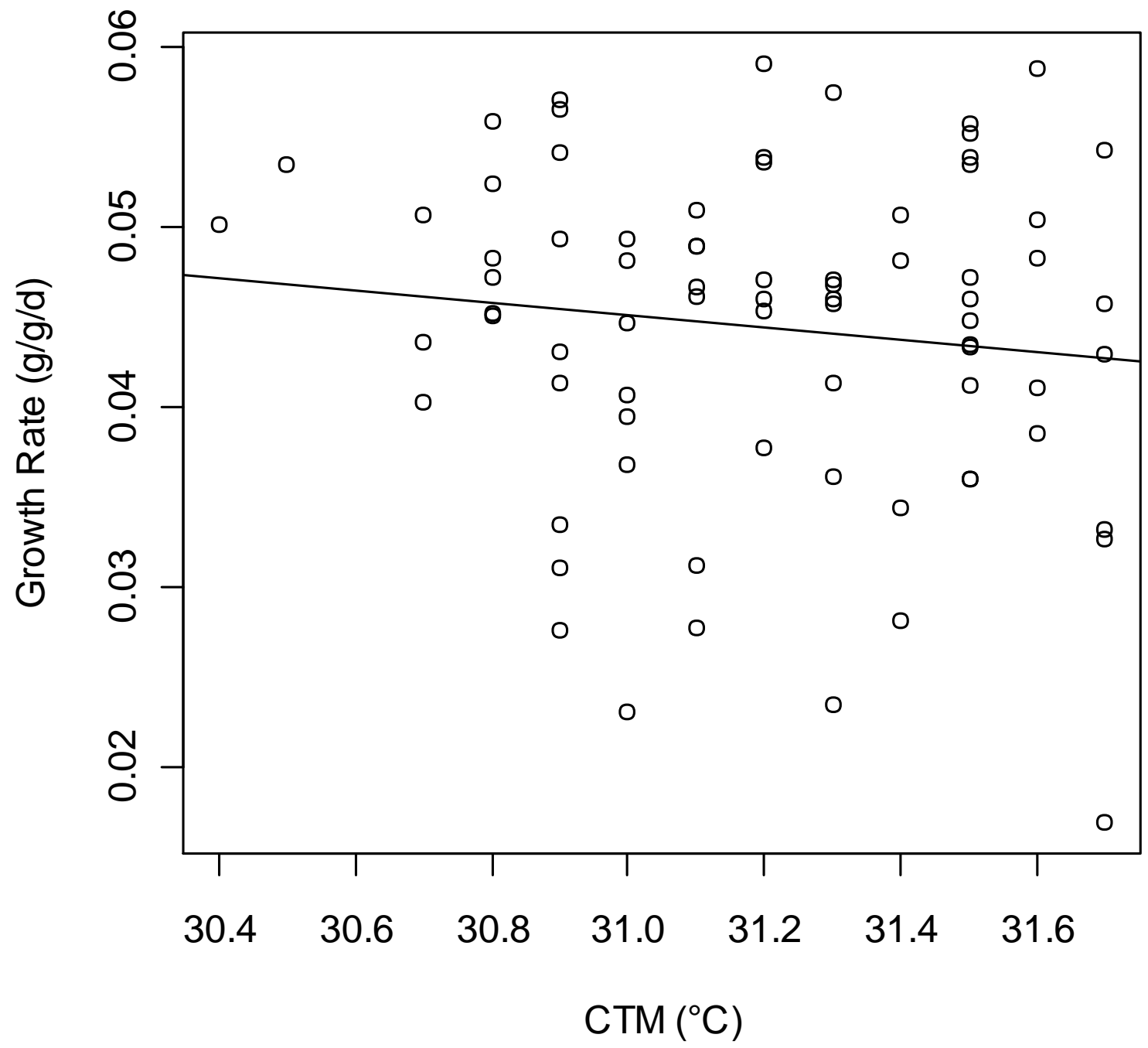

Figure 3.3. Scatter plot depicting the negative correlation between CTM and growth rate among all individuals tested at $20^{\circ} \mathrm{C}$. This relationship was not significant $(p=0.31)$. 


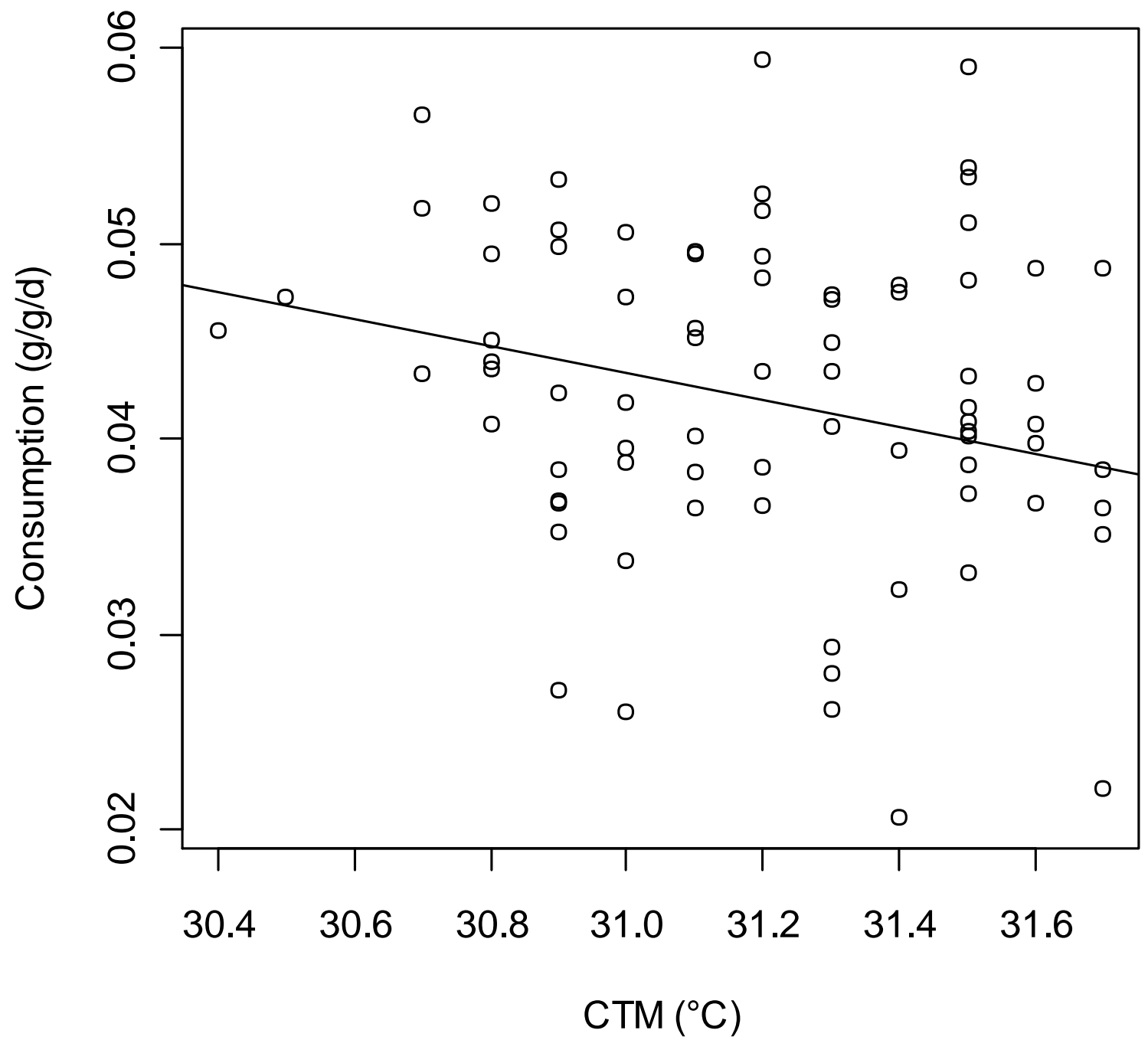

Figure 3.4. Scatter plot depicting the negative correlation between CTM and consumption among all individuals tested at $22^{\circ} \mathrm{C}$. This relationship was not significant $(p=0.11)$. 


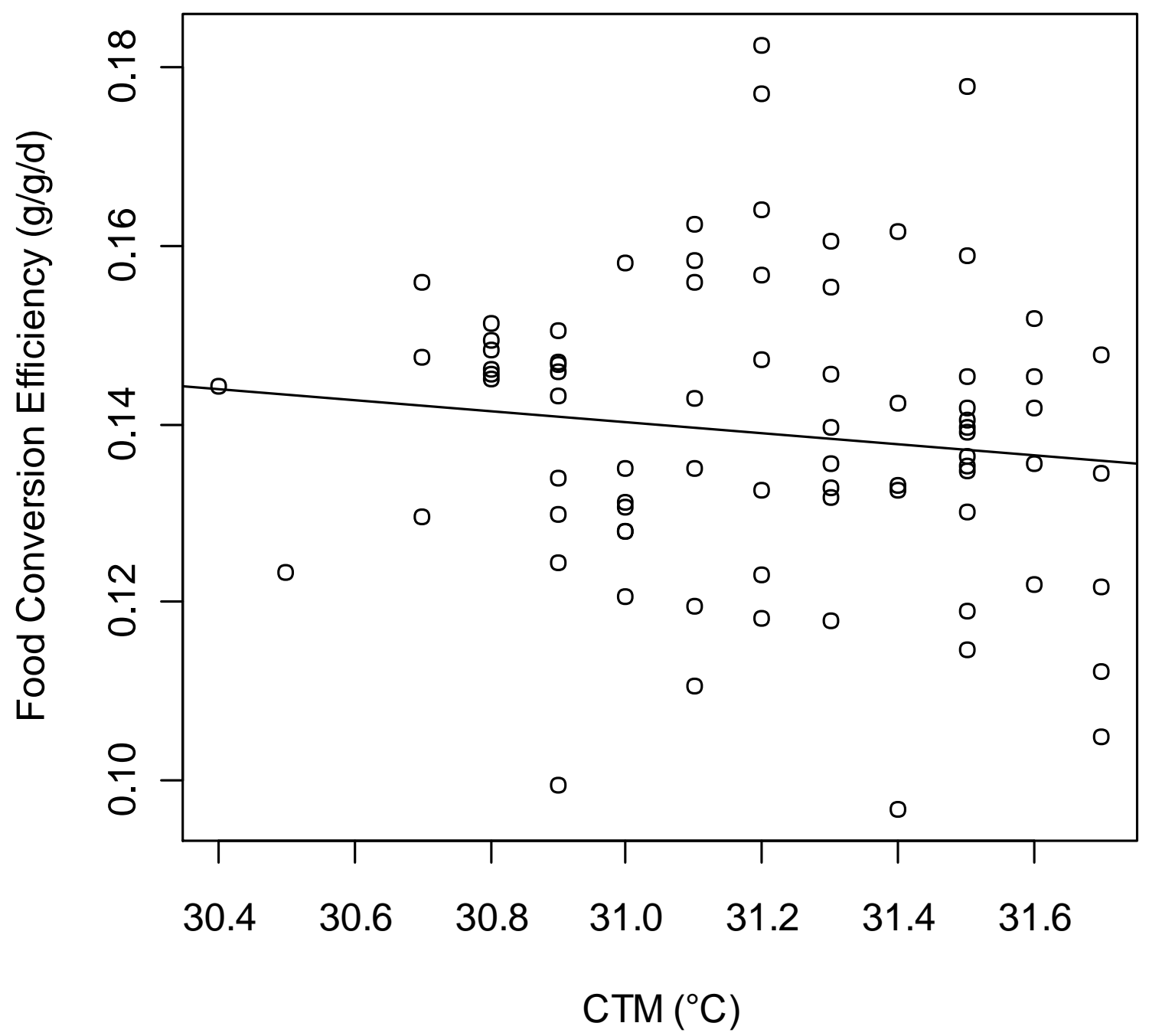

Figure 3.5. Scatter plot depicting the negative correlation between CTM and FCE among all individuals tested at $22^{\circ} \mathrm{C}$. This relationship was not significant $(p=0.33)$. 


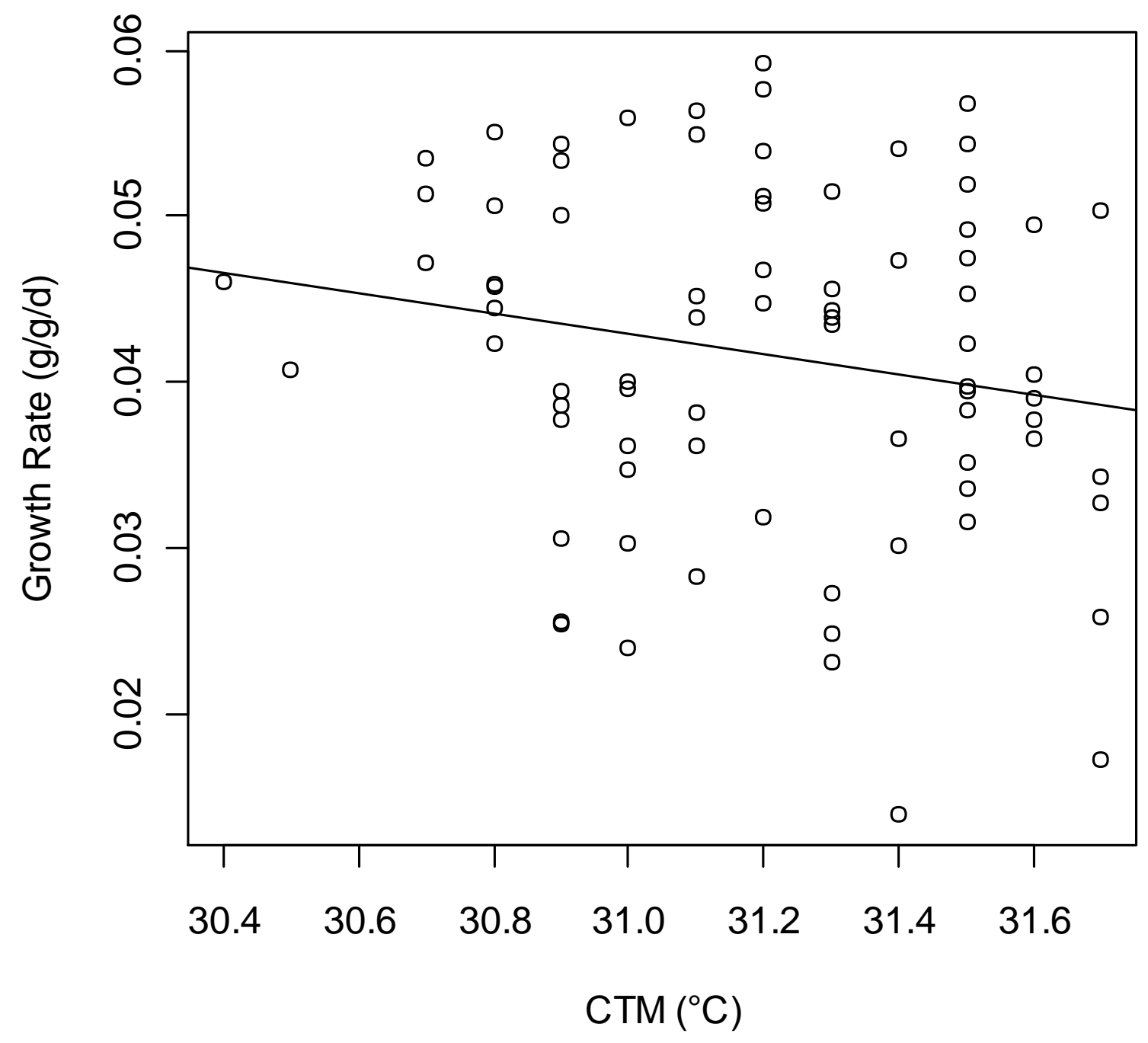

Figure 3.6. Scatter plot depicting the negative correlation between CTM and growth rate among all individuals tested at $22^{\circ} \mathrm{C}$. This relationship was not significant $(p=0.10)$. 


\section{Appendix A: Summary of Results Using Size Corrected Data}

In this appendix, results from the third chapter of this thesis are presented having corrected for differences in the initial size of fish used in the growth experiments. Research has shown that larger fish have lower specific metabolic and consumption rates when compared to smaller fish of the same species (Jobling 1983). This relationship causes comparisons between different sized individuals to be biased towards smaller fish having higher consumption and growth rates. In the analysis of the data presented in this appendix, we used previously published allometric bioenergetics values for rainbow trout to correct for any bias these differences in initial sizes may have had on our results. We used a coefficient of -0.30 to correct for differences in consumption rates and a coefficient of -0.217 to correct for differences in metabolic rates (Railsback and Rose 1999; Rand et al. 1993). 
Table A.1. Mean ( \pm SEM) consumption, food conversion efficiency (FCE) and growth rates of each strain at each test temperature after being corrected for differences in initial size. Statistical differences between strains within a temperature are denoted by different superscripted letters. Statistical differences between temperatures within a strain are denoted by *

\begin{tabular}{cccccc}
\hline Temperature & Strain & $\mathrm{N}$ & Consumption $(\mathrm{g} / \mathrm{g} / \mathrm{d})$ & $\mathrm{FCE}(\mathrm{g} / \mathrm{g} / \mathrm{d})$ & Growth Rate $(\mathrm{g} / \mathrm{g} / \mathrm{d})$ \\
\hline $20^{\circ} \mathrm{C}$ & Wytheville & 19 & $0.048 \pm 0.002^{\mathrm{A}}$ & $0.160 \pm 0.004^{\mathrm{A} *}$ & $0.051 \pm 0.002^{\mathrm{A}}$ \\
& Kamloop & 30 & $0.046 \pm 0.002^{\mathrm{A}}$ & $0.150 \pm 0.004^{\mathrm{AB}}$ & $0.047 \pm 0.001^{\mathrm{A}}$ \\
& Case Western & 27 & $0.034 \pm 0.001^{\mathrm{B}}$ & $0.144 \pm 0.004^{\mathrm{B} *}$ & $0.035 \pm 0.002^{\mathrm{B}}$ \\
\hline $22^{\circ} \mathrm{C}$ & Wytheville & 19 & $0.047 \pm 0.002^{\mathrm{A}}$ & $0.148 \pm 0.004^{\mathrm{A} *}$ & $0.048 \pm 0.003^{\mathrm{A}}$ \\
& Kamloop & 30 & $0.047 \pm 0.001^{\mathrm{A}}$ & $0.142 \pm 0.003^{\mathrm{A}}$ & $0.046 \pm 0.001^{\mathrm{A}}$ \\
& Case Western & 29 & $0.034 \pm 0.001^{\mathrm{B}}$ & $0.130 \pm 0.003^{\mathrm{B} *}$ & $0.032 \pm 0.002^{\mathrm{B}}$ \\
\hline
\end{tabular}

Table A.2. Summary of linear regression analysis relating CTM to consumption, FCE and growth at 20 and $22^{\circ} \mathrm{C}$. Data has been corrected for differences in initial size.

\begin{tabular}{ccccccc}
\hline Temperature & Variable & $\mathrm{N}$ & Slope & Intercept & $\mathrm{R}^{2}$ & $\mathrm{p}$-value \\
\hline $20^{\circ} \mathrm{C}$ & Consumption & 76 & -0.0038 & 0.1607 & 0.0145 & 0.2994 \\
& FCE & 76 & -0.0091 & 0.4348 & 0.0212 & 0.2096 \\
& Growth & 76 & -0.0056 & 0.2169 & 0.0274 & 0.1528 \\
\hline $22^{\circ} \mathrm{C}$ & Consumption & 78 & -0.0069 & 0.2576 & 0.0462 & 0.0587 \\
& FCE & 78 & -0.0060 & 0.3265 & 0.0126 & 0.3282 \\
& Growth & 78 & -0.0074 & 0.2726 & 0.0383 & 0.0860 \\
\hline
\end{tabular}




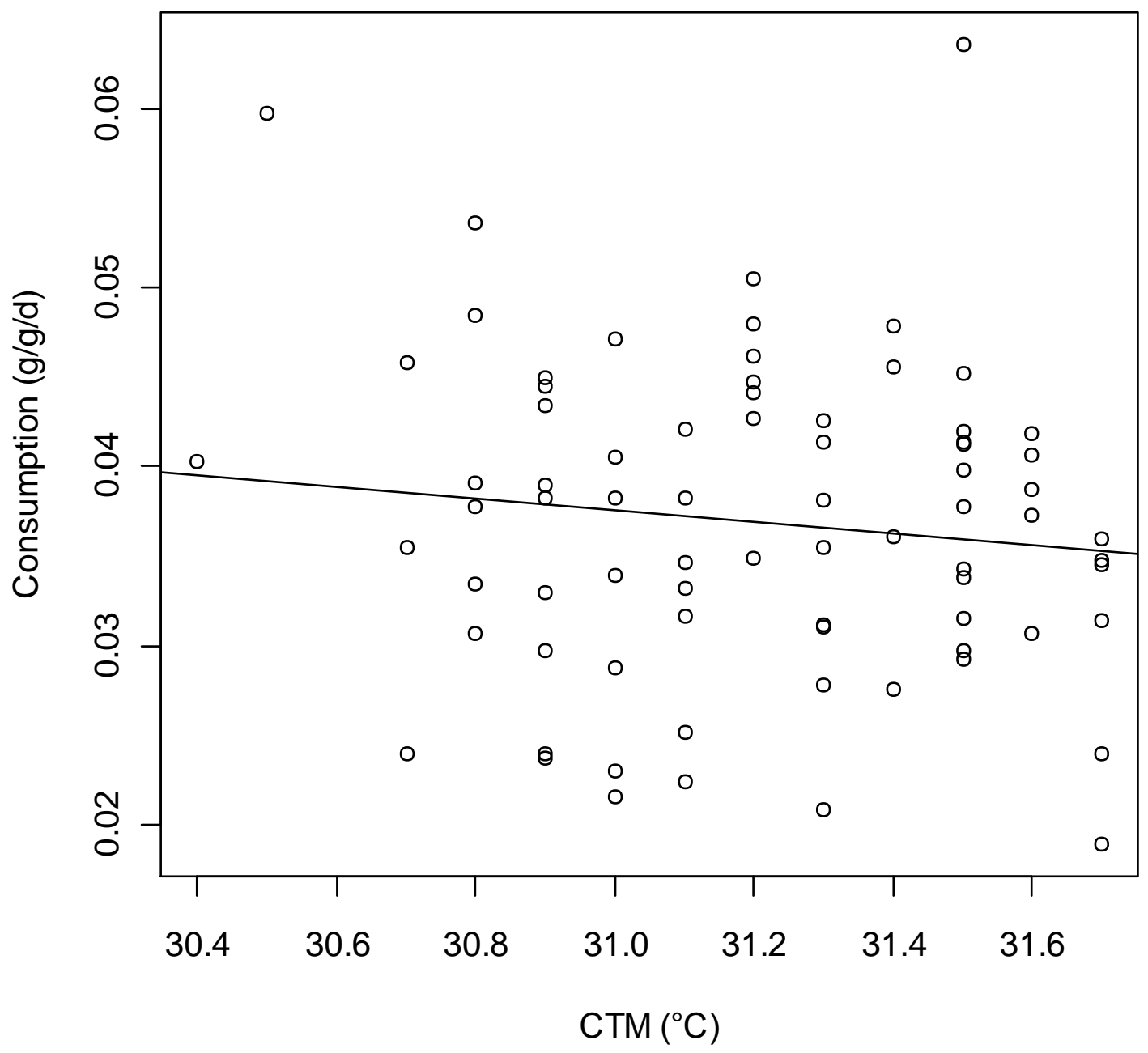

Figure A.1. Scatter plot depicting the negative correlation between CTM and consumption among all individuals tested at $20^{\circ} \mathrm{C}$ after being corrected for differences in initial size. This relationship was not significant $(p=0.30)$. 


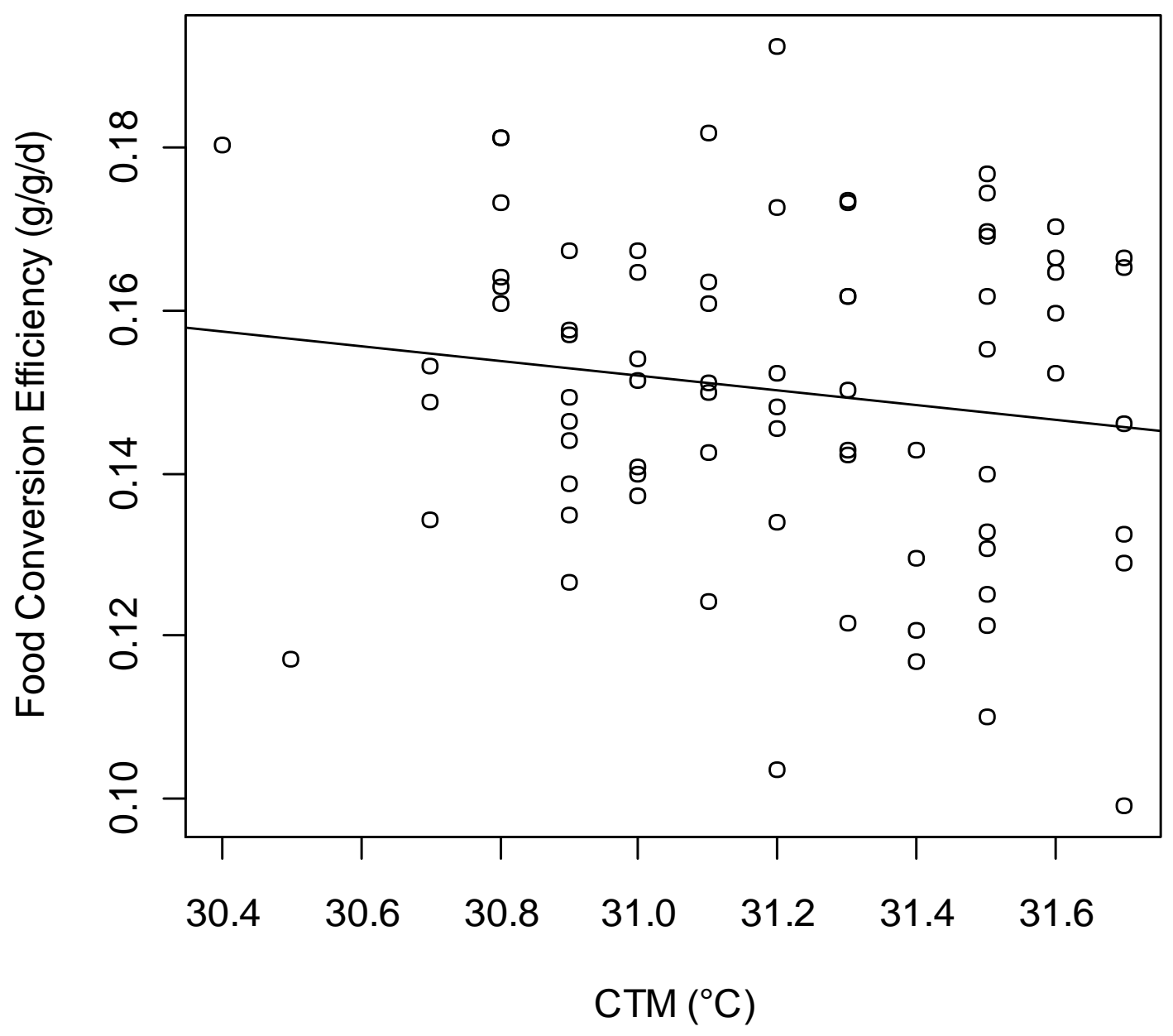

Figure A.2. Scatter plot depicting the negative correlation between CTM and FCE among all individuals tested at $20^{\circ} \mathrm{C}$ after being corrected for differences in initial size. This relationship was not significant ( $p$ $=0.21$. . 


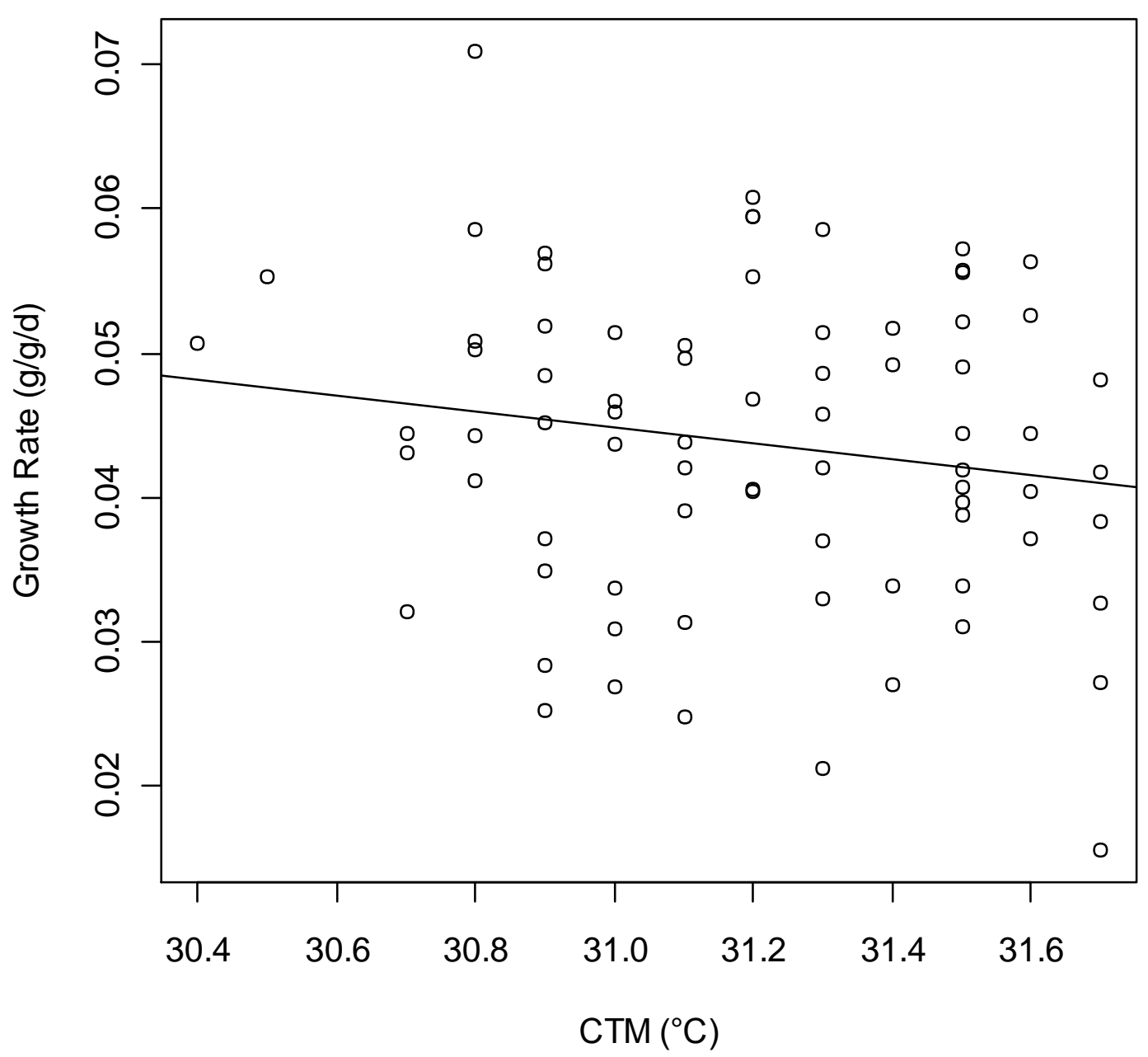

Figure A.3. Scatter plot depicting the negative correlation between CTM and growth rate among all individuals tested at $20^{\circ} \mathrm{C}$ after being corrected for differences in initial size. This relationship was not significant $(p=0.15)$. 


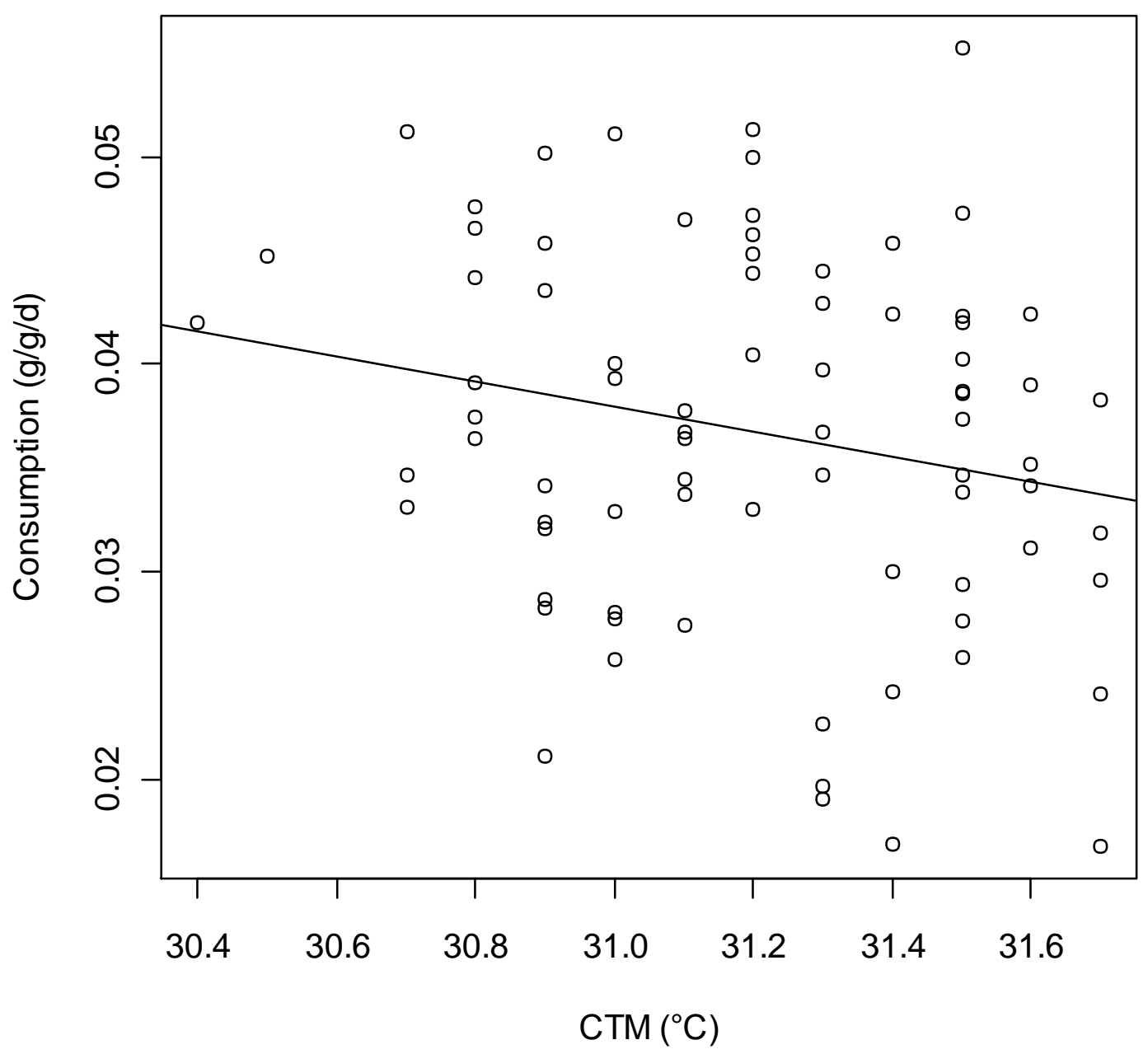

Figure A.4. Scatter plot depicting the negative correlation between CTM and consumption among all individuals tested at $22^{\circ} \mathrm{C}$ after being corrected for differences in initial size. This relationship was not significant $(p=0.06)$. 


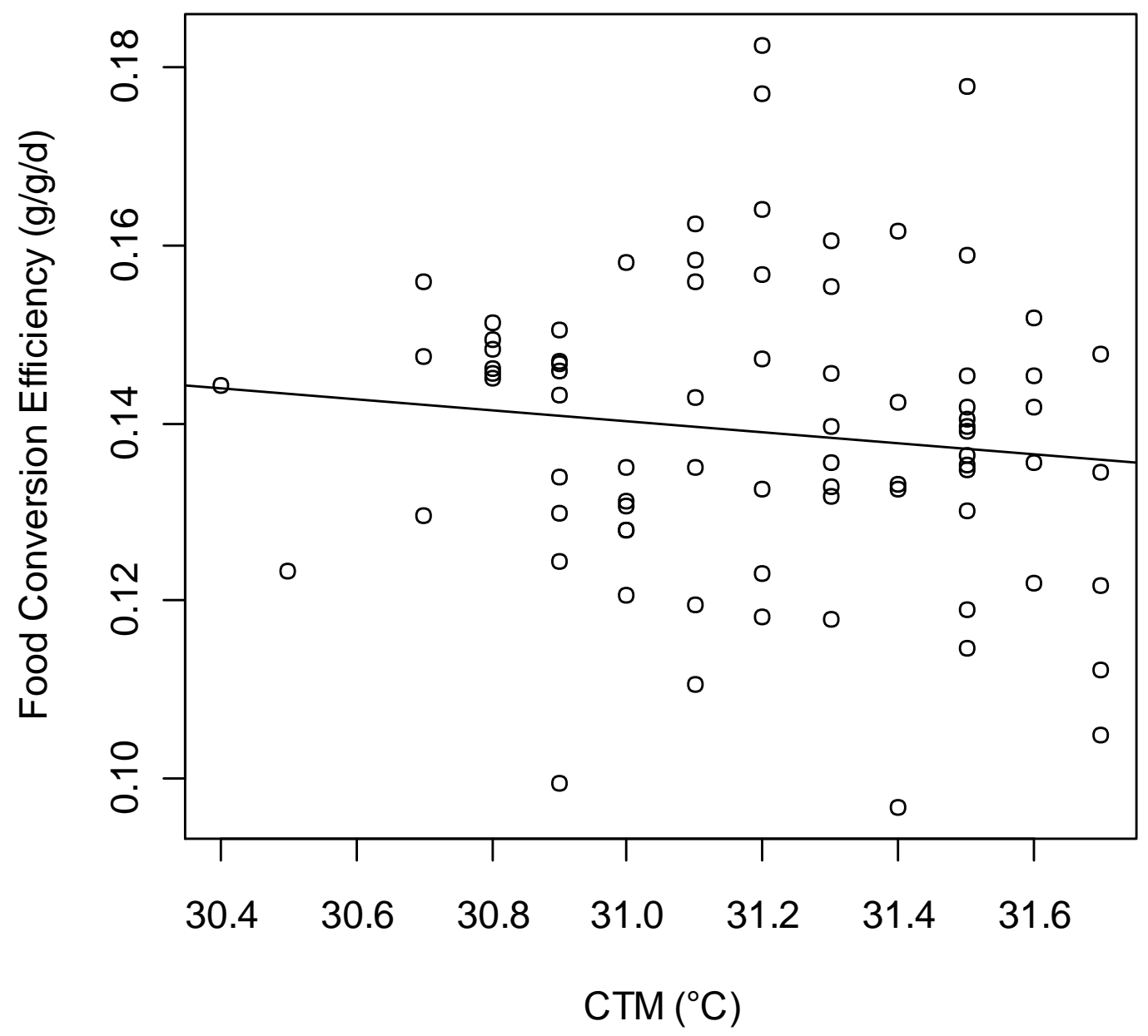

Figure A.5. Scatter plot depicting the negative correlation between CTM and FCE among all individuals tested at $22^{\circ} \mathrm{C}$ after being corrected for differences in initial size. This relationship was not significant ( $p$ $=0.33)$. 


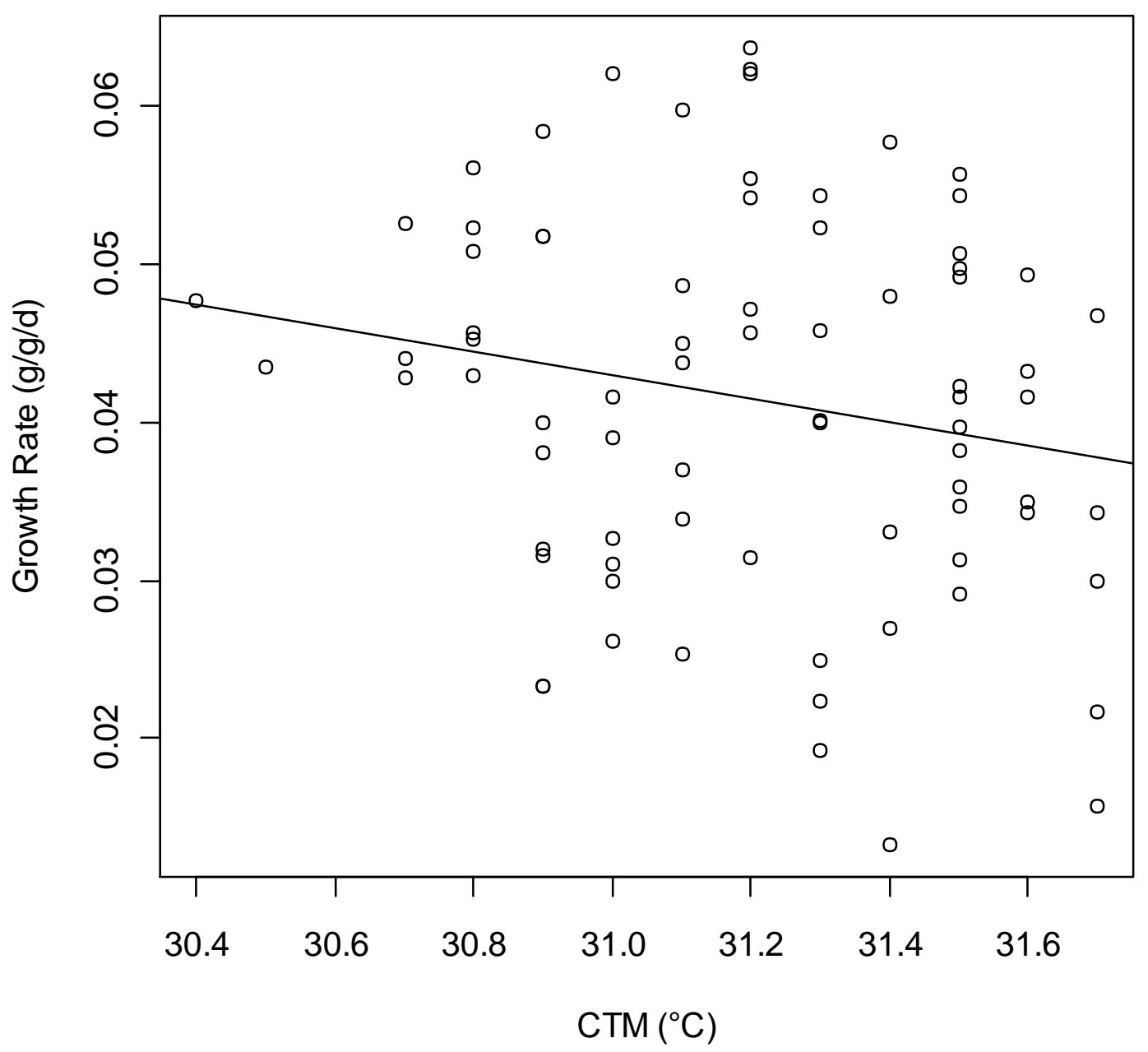

Figure A.6. Scatter plot depicting the negative correlation between CTM and growth rate among all individuals tested at $22^{\circ} \mathrm{C}$ after being corrected for differences in initial size. This relationship was not significant $(p=0.08)$. 